\title{
Experimental and Numerical Study of Swirling Diffusion Flame Provided by a Coaxial Burner: Effect of Inlet Velocity Ratio
}

\author{
Sawssen Chakchak ${ }^{1,2,3}$, Ammar Hidouri ${ }^{2}$, Hajar Zaidaoui ${ }^{1}$, Mouldi Chrigui ${ }^{4}$ and Toufik Boushaki ${ }^{1, *}$ \\ 1 ICARE CNRS, Université d'Orléans, Avenue de la Recherche Scientifique, 45071 Orléans, France; \\ sawssen.chakchak@cnrs-orleans.fr (S.C.); hajar.zaidaoui@cnrs-orleans.fr (H.Z.) \\ 2 Research Unit MEER, Faculty of Sciences of Gafsa, University of Gafsa, 2112 Gafsa, Tunisia; \\ ammar_hidouri@yahoo.fr \\ 3 National Engineering School of Monastir, University of Monastir, 5019 Monastir, Tunisia \\ 4 National Engineering School of Gabes, University of Gabes, 6000 Gabes, Tunisia; mouldi.chrigui@enig.rnu.tn \\ * Correspondence: toufik.boushaki@cnrs-orleans.fr; Tel.: +33-23-825-5070
}

Citation: Chakchak, S.; Hidouri, A.; Zaidaoui, H.; Chrigui, M.; Boushaki, T. Experimental and Numerical Study of Swirling Diffusion Flame Provided by a Coaxial Burner: Effect of Inlet Velocity Ratio. Fluids 2021, 6, 159 https://doi.org/10.3390/fluids6040159

Academic Editor: Madjid Birouk

Received: 16 March 2021

Accepted: 13 April 2021

Published: 16 April 2021

Publisher's Note: MDPI stays neutral with regard to jurisdictional claims in published maps and institutional affiliations.

Copyright: (c) 2021 by the authors. Licensee MDPI, Basel, Switzerland. This article is an open access article distributed under the terms and conditions of the Creative Commons Attribution (CC BY) license (https:// creativecommons.org/licenses/by/ $4.0 /)$.

\begin{abstract}
This paper reports an experimental and numerical investigation of a methane-air diffusion flame stabilized over a swirler coaxial burner. The burner configuration consists of two tubes with a swirler placed in the annular part. The passage of the oxidant is ensured by the annular tube; however, the fuel is injected by the central jet through eight holes across the oxidizer flow. The experiments were conducted in a combustion chamber of $25 \mathrm{~kW}$ power and $48 \times 48 \times 100 \mathrm{~cm}^{3}$ dimensions. Numerical flow fields were compared with stereoscopic particle image velocimetry (stereo-PIV) fields for non-reacting and reacting cases. The turbulence was captured using the Reynolds averaged Navier-Stokes (RANS) approach, associated with the eddy dissipation combustion model (EDM) to resolve the turbulence/chemistry interaction. The simulations were performed using the Fluent CFD (Computational Fluid Dynamic) code. Comparison of the computed results and the experimental data showed that the RANS results were capable of predicting the swirling flow. The effect of the inlet velocity ratio on dynamic flow behavior, temperature distribution, species mass fraction and the pollutant emission were numerically studied. The results showed that the radial injection of fuel induces a partial premixing between reactants, which affects the flame behavior, in particular the flame stabilization. The increase in the velocity ratio $\left(R_{v}\right)$ improves the turbulence and subsequently ameliorates the mixing. $\mathrm{CO}$ emissions caused by the temperature variation are also decreased due to the improvement of the inlet velocity ratio.
\end{abstract}

Keywords: diffusion flame; swirling flame; stereo-PIV; eddy dissipation model; pollutant emissions

\section{Introduction}

Among the essential aims of combustion research is to increase the efficiency of combustion and minimize the production of pollutants. Generally, there are three primary types of flame-the premixed flame, the partially premixed flame and the non-premixed flame (diffusion flame). The diffusion flame is widely employed in industrial applications. Thus, practical combustion systems such as combustion furnaces, diesel engines and rocket engines use non-premixed flames due to their safety and better flame stability compared to a premixed flame [1]. In this process, oxidant and fuel are injected separately into the flame to limit the flashback and explosion. Several studies have shown that turbulent diffusion flame fields play an important role in reducing atmospheric pollution and maintaining the stability of the flame, and thus the good performance of combustion systems [2-4]. The stabilization of turbulent flames can be accomplished by the use of a swirl burner. Several experimental investigations have been carried out in this field [5-9]. The use of swirling flames can also enhance the mixing of the reactant, generating a compact and intense flame, 
improving combustion efficiency and reducing some pollutant emissions $[10,11]$. If the swirl intensity is very high, the mixing can be disturbed and pollutant emissions can be increased [12]. In the case of a non-premixed flame, the high swirl intensity induces flame blow-off and instabilities of combustion. Thus, the ultimate goal is the use of an optimum swirl intensity to achieve flame stability and control. The optimum swirl intensity value must be proportional to the higher mixing between the reactants, with a homogeneous distribution of temperature in order to maximize the combustion efficiency and minimize the pollutant emissions.

Detailed experimental measurements facilitate the optimization of the combustor. Thus, the use of optical measuring methods in the case of reacting turbulent flows is preferable in order to obtain reliable experimental data. The stereo particle image velocimetry (SPIV) technique allows us to obtain the quantitative information on the spatial distributions of the instantaneous flow velocity. Boushaki et al. [13] presented experiments of swirling turbulent flames using the SPIV technique. The study was carried out on a burner of around of $15 \mathrm{~kW}$ ( $240 \mathrm{~L} / \mathrm{min}$ of oxidant) of power and focused on the study of average flow fields. There are challenges in the experimental study of very complex flow fields and turbulence processes. In fact, experimental measurements in full-scale burners are rarely possible and very expensive. Recently, due to the rapid development of the computing innovations and mathematical calculations, the technology of computational fluid dynamics (CFD) has been showing great progress, which has provided reliable tools and conveniences for the researchers of very complex fluid movement. CFD can be very useful in providing important information on the flow field, chemical reaction and temperature distribution in the combustion chamber [14]. Many studies on the computational of swirling flows and turbulent flames have made use of Reynold average Navier-stokes (RANS) equations [15-17]. Mansouri et al. [18] studied the swirling flame numerically. They reported that the realizable k- $\varepsilon$ (RKE) RANS model performs reasonably well with swirling flows compared with other RANS models (standard k- $\varepsilon$ and k- $\omega$ SST). Fu et al. [19] used four turbulence models-the standard $k-\varepsilon$, the realizable $k-\varepsilon$, the RNG $k-\varepsilon$ and the SST k- $\omega$ models- to simulate the flow field over a swirl burner. The results of the calculation using the realizable $\mathrm{k}-\varepsilon$ model were more accurate than those of the other models. Reis et al. [20] numerically studied the turbulent natural gas flow through a non-premixed industrial burner of a slab preheating furnace. They compared different turbulence models,

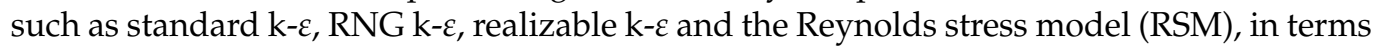
of velocity profiles, pressure drop and orifice discharge coefficients. The numerical results were compared with the experimental data and they found that the realizable k- $\varepsilon$ model appeared to be a correct turbulence model. Mansouri and Boushaki [21,22] carried out a numerical simulation of a turbulent non-premixed swirling burner using two different models; RANS calculations and delayed-detached eddy simulation (DDES), under non-reacting and reacting cases. The comparison between the computed results and experimental data showed that both RANS and DDES obtained the distribution of axial velocity, tangential velocity and temperature. Hidouri et al. [23] studied turbulent diffusion flames using the first-order $\mathrm{k}-\varepsilon$ model, along with two different methods for the sub-model, describing the scalar dissipation rate. They showed that the use of a non-equal scale model improved the obtained numerical results. The mixing process between the isotherm and reacting jets was investigated numerically by Hidouri et al. and Yahya et al. [24-26]. The study showed that the mixing was enhanced using separated jet burners compared to a simple jet burner. Several works showed that the eddy dissipation combustion model (EDM) was able to resolve turbulence/chemistry interaction. Achim et al. [27] used the EDM to study a full-scale coal combustion model of a tangential fired boiler. Their results were in good agreement with the experimental data. Lopez-Parra and Turan [28] investigated the effect of fuel inlet flow excitation on the soot formation and NO formation of a methane turbulent jet diffusion flame using the EDM and standard $\mathrm{k}-\varepsilon$ model. The prediction results of the flame temperature and mixture fraction showed good agreement with experiments. 
Baik and Kim [29] used the EDM to investigate the combustion of fuel and oxygen in a combustion chamber linked to a nozzle in a high velocity oxygen fuel (HVOF).

Inlet dynamic conditions have an important effect on flame structure and stability. Several studies on non-reacting shear coaxial jets have shown that one of the most influential factors in the mixing between the inner and external jets in a coaxial burner is the velocity ratio of the jets [30-32]. Another investigation was presented by Wu and Essenhigh [33] for a laminar methane inverse diffusion flame over a simple coaxial burner. They studied this type of flow using different air-fuel velocities. The numerical profile of temperature and species agree well with the experimental data presented by them. Imine et al. [34] numerically investigated the influence of a directed co-flow on a non-restive turbulent axisymmetric jet using variable density. Their results indicated that the directed co-flow with a positive angle considerably enhanced the mixing. For methane-oxygen shear coaxial jet flames, several studies have investigated their combustion stability and jet velocity [35-37]. Most of the previous studies regarding the investigation of the inlet velocity conditions provided by coaxial reacting jets were conducted on cases where the inner jet and the outer jet delivered flows in the same direction. However, studies concerning the effect of this parameter in the case where the fuel is injected across the oxidizer are very limited.

This paper investigates the effect of dynamic inlet boundary conditions on the thermophysical flame structure provided by a coaxial jet burner in which the fuel was injected across the oxidizer through eight holes. The burner configuration consisted of two coaxial tubes with a swirler placed in the annular part. The annular part supplied the oxidant; however, the central tube delivered the fuel through eight holes placed radially at the burner exit. Three velocity ratios of $0.5,1$ and 1.5 were tested. The fuel and oxidizer were injected under normal conditions of pressure and temperature.

\section{Experimental Setup}

Figure 1 shows the burner configuration used in this study. The burner was composed of two coaxial jets with a central tube of outside diameter $D_{i}=15 \mathrm{~mm}$ and inner diameter $D_{\text {in }}=12 \mathrm{~mm}$, which ensured the passage of methane (see Figure 1).
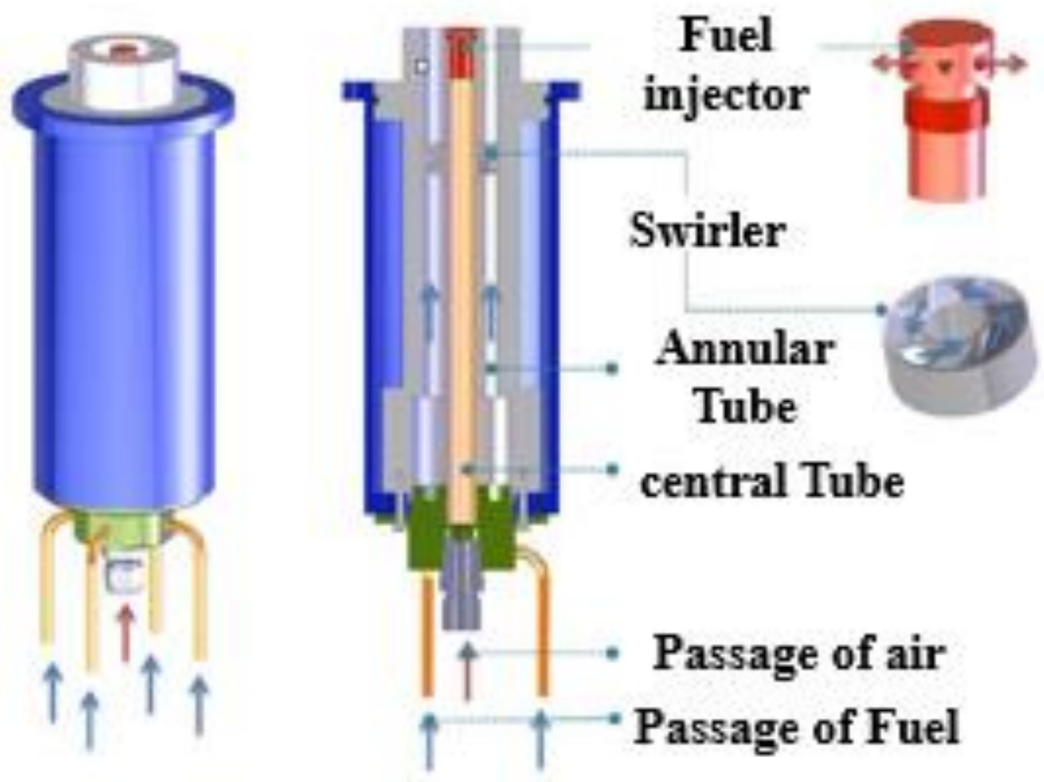

Figure 1. Schematic view of the burner.

The annular tube of diameter $D_{e}=38 \mathrm{~mm}$ ensured the passage of air by means of four tubes from the bottom. An injector placed at the end of the central tube had eight uniformly distributed holes ( $3 \mathrm{~mm}$ in diameter) for a lateral injection of the methane across the annular air flow. The fuel injector was used to promote mixing in the vicinity of the burner outlet. 
The swirler placed in the annular part, $60 \mathrm{~mm}$ from the exit burner, ensured the rotation of the air. The swirler used in this work was composed of eight vanes with a fixed angle. The degree of swirl for rotating flows is usually characterized by the non-dimensional swirl number $S_{n}$ (Boushaki et al. [13]). The swirl number is based on the equation of Beer and Chigier [38]. In this study the swirl number was equal to 1.4. The burner was placed in a combustion chamber of a square section of $48 \times 48$ and $100 \mathrm{~cm}^{3}$ height, plus a convergent section of $20 \mathrm{~cm}$ high with a final circular section of $10 \mathrm{~cm}$. The rigid refractory panels with low thermal conductivity $\left(0.06 \mathrm{~W} / \mathrm{m} \mathrm{k}\right.$ at $\left.200{ }^{\circ} \mathrm{C}\right)$ ensured the insulation and protection of the internal wall of the combustion chamber. The walls were cooled from outside via a flow of water at ambient temperature.

The stereo-PIV technique was used in this study to characterize the flow structure and to analyze the flow dynamics in three dimensions $(x, y, z)$. The stereo-PIV setup included a $2 \times 130 \mathrm{~mJ} \mathrm{Nd}$ :YAG laser with a double pulse (Quantel CFR200,532 nm, $10 \mathrm{~Hz}$, Lannion, France) and two CDD cameras of $2048 \times 2048$ pixels from JAI (RM-4200CL, 12 bits, San Hose, CA, USA). Both cameras use d aScheimpflug adapter and were oriented on the corresponding side of the laser sheet. The cameras were equipped with two Carl Zeiss Milvus lenses (Makro-Planar T, 100 mm f/2 ZF.2, Marly-le-Roin, France). In front of each camera, there was an interference filter of $532 \mathrm{~nm} \pm 5$ to reduce the flame signal. Note that the windows of the combustion chamber were in quartz and did not affect the quality of the measurements. There were also no disturbances caused by soot because this gaseous combustion with stochiometric conditions produces hardly any soot. To set up the stereoscopic assembly, the cameras were oriented at $+45^{\circ}$ and $-45^{\circ}$ relative to the measurement plane. Experiments were performed in the axial plane of the flow in reacting and non-reacting conditions. The light sheet had a thickness of $200 \mu \mathrm{m}$ in order to minimize out-of-sheet particle displacements of the swirling flow between the double laser pulses. The time between the two laser pulses was set at $30 \mu \mathrm{s}$. The size of the measurement field was $90 \times 90 \mathrm{~mm}$, with 500 pairs of images for each camera. The images were acquired and processed using Dantec Dynamic Studio software (Skovlunde, Denmark). The calibration was performed using a double-sided test pattern made in the laboratory, a displacement system and the Multi Calibration function, using Dynamic Studio software. The processing comprised several steps: the acquisition of S-PIV images, the subtraction of the background noise using the mean image, the extraction of the lower part of the image containing false vectors using the the ROI extract function, the calculation of velocity vectors based on pairs of particle images (adaptive PIV) and the calculation and reconstruction of velocity vectors with the three components by combining the 2D data collected from the two cameras.

The size of the S-PIV calculation interrogation window was $32 \times 32$ pixels, which corresponds to $1.57 \times 1.57 \mathrm{~mm}^{2}$ in physical size (1 pixel $\left.=0.049 \mathrm{~mm}\right)$, with $50 \%$ overlap. The vectors of velocity were calculated using the cross-correlation algorithm. For a maximum particle displacement of eight pixels, this corresponded to less than $5 \%$ uncertainty in the final velocity obtained.

Micro-metric $\mathrm{ZrO}_{2}$ particles were used for flow seeding and were injected into the coaxial tube. This choice of Zirconium Oxide particles was due to their very good resistance to the temperature generated by the combustion (melting temperature 2988K), and their good refractive index (2.2), which allows good light scattering, and their small size ( $1 \mu \mathrm{m}$ in diameter on average). The particle rate was controlled by valves through the gas flow rate in the seeding line. The particles were dried before measurements, in order to limit agglomerates. The criterion assuring a good track of flow by particles was respected here, since the Stokes number obtained in the case of our experiments was lower than $1(\mathrm{St}<<1)$. The Stokes number is given by the ratio between the response time of particles $\left(t_{p}\right)$ and a time characteristic of the flow $\left(t_{\mathrm{f}}\right)$. Note that the validity of stereo-PIV calibration with high temperature was checked. We compared some data to 2D PIV measurements and also to LDA measurements, the data were similar. 


\section{Numerical Modeling}

Governing equations were discretized using the finite volume method. The pressurevelocity coupling was achieved by the use of the SIMPLE algorithm [22]. The realizable $\mathrm{K}-\varepsilon$ turbulence model was used in order to close the system of Reynolds Navier-Stokes equations. The eddy dissipation model (EDM) was used as the turbulence-interaction model with the assumption of a two-step reaction [18].

\subsection{Gouverning Equations}

The numerical simulation of turbulent reactive flow is obtained by the resolution of the partial differential equation of the conservation of mass, momentum, energy and species [38]. The mass conservation equation is written as follows:

$$
\frac{\partial \rho}{\partial t}+\frac{\partial}{\partial x_{i}}\left(\rho V_{i}\right)
$$

where $\rho$ represents the density and $V_{i}$ is the component of the instantaneous velocity in three directions $(i=1,2,3)$. In the general case, the momentum conservation equation can be given by:

$$
\frac{\partial}{\partial t}\left(\rho V_{i}\right)+\frac{\partial}{\partial x_{i}}\left(\rho V_{i} V_{j}\right)=-\frac{\partial P}{\partial x_{j}}+\frac{\partial \tau_{i j}}{\partial x_{i}}+\rho g_{i}
$$

where $P$ is the pressure, $\rho g_{i}$ defines the result of the volumetric forces generated by gravity and $\tau_{i j}$ represents the viscous stress tensor:

$$
\tau_{i j}=\mu\left[\left(\frac{\partial V_{i}}{\partial x_{j}}+\frac{\partial V_{j}}{\partial x_{i}}\right)-\frac{2}{3} \delta_{i j} \frac{\partial V_{i}}{\partial x_{i}}\right]
$$

where $\mu$ represents the dynamic molecular viscosity.

The energy equation is written as follows:

$$
\frac{\partial(\rho h)}{\partial t}+\frac{\partial}{\partial x_{i}}\left(\rho V_{i} h\right)=\frac{\partial}{\partial x_{i}}\left(\rho D_{h} \frac{\partial h}{\partial x_{i}}-\rho \overline{h^{\prime} V_{i}^{\prime}}\right)
$$

In this equation, $D_{h}=\frac{\lambda}{\rho c_{p}}$ represents the thermal diffusivity, $-\rho \overline{h^{\prime} V^{\prime}}$ is the correlation term between the velocity and the enthalpy fluctuation. The specific enthalpy $h$ is given by [38]:

$$
h=\sum_{l=1}^{n} Y_{l} h_{l}
$$

The conservation equation of species can be written as [38]:

$$
\frac{\partial\left(\rho Y_{l}\right)}{\partial t}+\frac{\partial\left(\rho V_{i} Y_{l}\right)}{\partial x_{i}}=-\frac{\partial J_{j}^{l}}{\partial x_{i}}+\rho \dot{W}_{l}
$$

where $Y_{l}, J_{i}^{l}$ and $\dot{W}_{l}$ represent respectively the mass fraction, the mass diffusion flux in the $i$ direction and the production rate of the species $l$.

\subsection{Turbulence Model}

In the case of turbulent flows, the introduction of the overall averages of Reynolds unveiled new unknown terms, originating from the non-linearity of the Navier-Stokes equations. These unknown factors are the turbulent kinetic energy and the dissipation rate of kinetic energy. The closing of the equation system requires the determination of these terms, which is the object of the different models of turbulence. In this paper, the realizable $\mathrm{K}-\varepsilon$ (KER) is used to simulate the turbulent flow. KER has a new formula for dissipation rate, an alternative formula for turbulent viscosity and is derived from a modified equation 
for the rate of $(\varepsilon)$, changed from an exact equation for the mean square of the vorticity fluctuations. The transport equations for $\mathrm{k}$ and $\varepsilon$ in the KER model are given by [39]:

$$
\begin{gathered}
\frac{\partial k}{\partial t}+\frac{\partial k V_{i}}{\partial x_{i}}=\frac{\partial}{\partial x_{i}}\left(D k_{e f f} \frac{\partial k}{\partial x_{i}}\right)+G_{k}-\varepsilon \\
\frac{\partial \varepsilon}{\partial t}+\frac{\partial \varepsilon V_{i}}{\partial x_{i}}=\frac{\partial}{\partial x_{i}}\left(D \varepsilon_{e f f} \frac{\partial \varepsilon}{\partial x_{i}}\right)+\sqrt{2} C_{1 \varepsilon} S_{i j} \varepsilon-C_{2 \varepsilon} \frac{\varepsilon^{2}}{k+\sqrt{v \varepsilon}}
\end{gathered}
$$

with the turbulent viscosity determined by:

$$
v_{t}=C_{\mu} \frac{k^{2}}{\varepsilon}
$$

where $C_{\mu}$ is computed by:

$$
\begin{aligned}
C_{\mu} & =\frac{1}{A_{0}+A_{S} \frac{U^{*} k}{\varepsilon}} \\
S & =\sqrt{2 S_{i j} S_{i j}}
\end{aligned}
$$

The viscosity coefficient $C_{\mu}$ in this model is a function of the averaged strain rate and the curl; it is computed from:

$$
\begin{gathered}
C_{\mu}=\frac{1}{A_{0}+A_{s} \frac{U^{*} k}{\varepsilon}} \\
U^{*}=\sqrt{S_{i j} S_{i j}+\widetilde{\Omega}_{i j} \widetilde{\Omega}_{i j}} \\
\widetilde{\Omega}_{i j}=\bar{\Omega}_{i j}-\varepsilon_{i j k} \omega_{k}-2 \varepsilon_{i j k} \omega_{k}
\end{gathered}
$$

where $\bar{\Omega}_{i j}$ is the mean rate of rotation tensor and $\omega_{k}$ is the angular velocity.

The constants $A_{0}$ and $A_{s}$ are determined as below:

$$
\begin{gathered}
A_{0}=4 ; A_{s}=\sqrt{6} \cos \phi \\
\phi=\frac{1}{3} \operatorname{arcos}(\min (\max (\sqrt{6} W,-1), 1)) \\
W=\frac{S_{i j} S_{j k} S_{k i}}{\widetilde{S}^{2}}
\end{gathered}
$$

$C_{1 \varepsilon}$ is computed by:

$$
\begin{gathered}
C_{1 \varepsilon}=\max \left(\frac{\eta}{5+\eta}, 0.43\right) \\
\eta=S\left(\frac{k}{\varepsilon}\right)
\end{gathered}
$$

\subsection{Combustion Modeling}

The eddy dissipation model (EDM), based on the work of Magnussen and Hjertager [40], is used in this paper. This model is used in the assumption of a one-step or two-step reaction. The EDM provides reasonable accuracy and convergence [41,42]. The net rate of production for species $l$ due to reaction $r$ is given by the two expressions below [18]:

$$
R_{l, r}=v_{l, r} M_{\omega, l} A \rho \frac{\varepsilon}{k} \min \left(\frac{Y_{R}}{v_{R, r} M_{\omega, R}}\right)
$$




$$
R_{l, r}=v_{l, r} M_{\omega, l} A B \rho \frac{\varepsilon}{k}\left(\frac{\sum_{P} Y_{P}}{\sum_{j}^{N} v_{j, r} M_{\omega, j}}\right)
$$

where $Y_{R}$ represents the mass fraction of a particular reactant $R, k$ is the turbulence kinetic energy, $M_{\omega}$ is the molecular mass of specie, $v$ is the stoichiometric coefficient, $Y_{P}$ is the mass fraction of any product species $\mathrm{P}$, and $\mathrm{A}$ and $\mathrm{B}$ are empirical constants fixed to 4 and 0.5 respectively. Two-step reaction mechanisms including six chemical species $\left(\mathrm{CH}_{4}, \mathrm{O}_{2}\right.$, $\left.\mathrm{CO}_{2}, \mathrm{CO}, \mathrm{H}_{2} \mathrm{O}, \mathrm{n}_{2}\right)$ are used in this work:

$$
\begin{gathered}
2 \mathrm{CH}_{4}+3 \mathrm{O}_{2} \rightarrow 2 \mathrm{CO}+4 \mathrm{H}_{2} \mathrm{O} \\
2 \mathrm{CO}+\mathrm{O}_{2} \rightarrow 2 \mathrm{CO}_{2}
\end{gathered}
$$

\subsection{Computational Domain and Boundary Conditions}

Figure 2 presents a schematic view of the numerical domain. The physical system includes the coaxial burner and the combustion chamber. The simulation is performed using the three-dimensional ANSYS-Fluent 16 code [41], in which the equations are solved by the finite volume method applied on a 4 million hexahedral mesh. The grid used was refined close to the burner exit to get more information in the reaction zone. Since we used a very fine mesh, the result remained unchanged beyond 4 million cells.

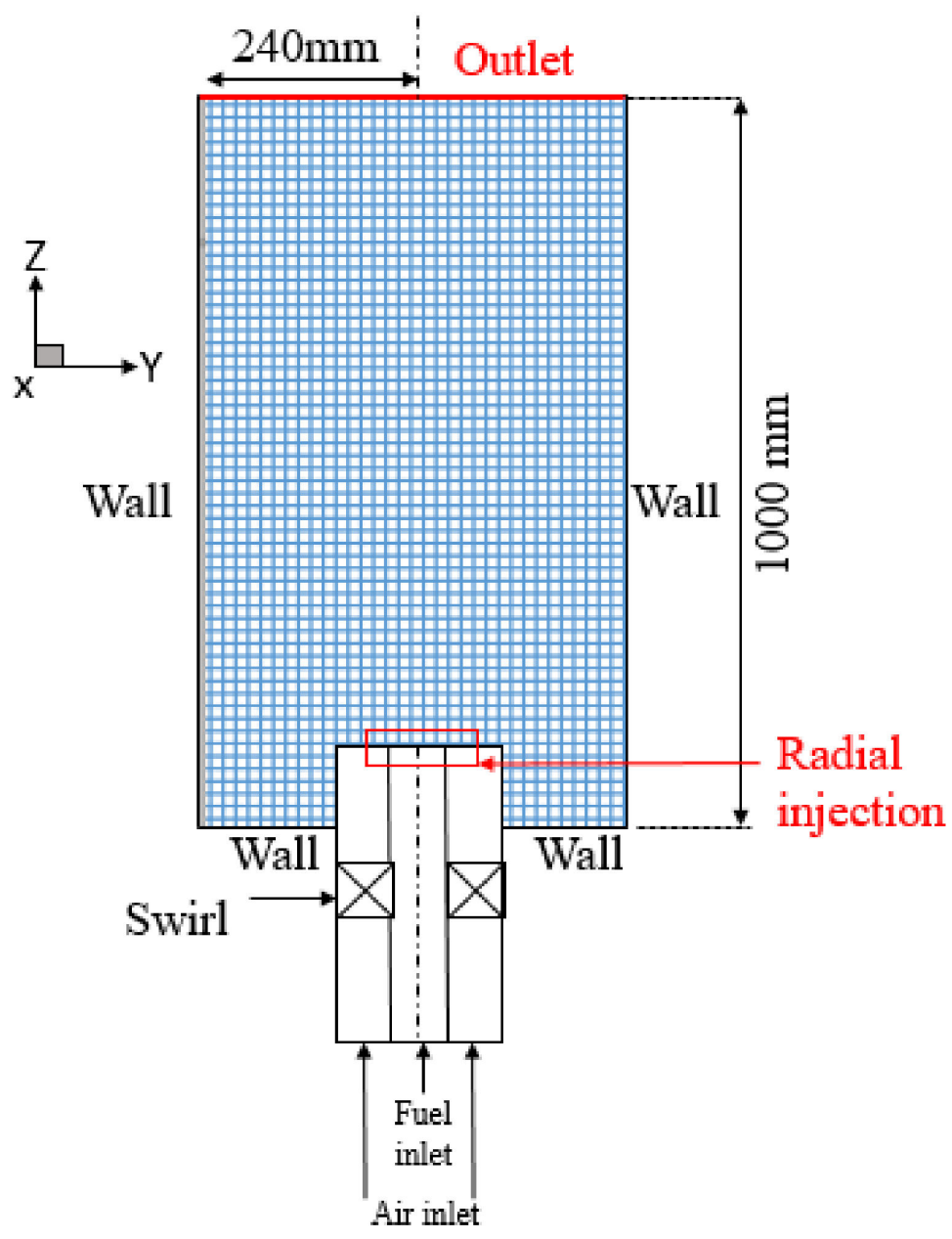

Figure 2. Computational domain. 
The boundary conditions were imposed as follows. At the air inlet, a mass flow boundary condition $\dot{m}_{\text {air }}$ was used (see Table 1). At the fuel inlet, $\mathrm{CH}_{4}$ was selected and mass flow inlet boundary condition $\dot{m}_{\text {ful }}$ was used (see Table 1). At the outlet, a static pressure was applied. The velocity ratio $\left(R_{v}\right)$ was calculated as the external mean velocity $\left(\mathrm{V}_{\mathrm{e}}\right)$ to the internal mean velocity $\left(\mathrm{V}_{\mathrm{i}}\right)$. There are three techniques to modify the velocity ratio; one is to change the external and the internal velocity at the same time, keeping the total mass flow rate of the jets constant. Another method consists of fixing $V_{i}$ and varying $\mathrm{V}_{\mathrm{e}}$. In the last technique, $\mathrm{V}_{\mathrm{e}}$ is kept constant, whereas $\mathrm{V}_{\mathrm{i}}$ is modified. In this work, $\mathrm{V}_{\mathrm{i}}$ was fixed to $4.98 \mathrm{~m} / \mathrm{s}$ (fuel velocity), whereas the velocity of the air was modified from $2.8 \mathrm{~m} / \mathrm{s}$ to $7.47 \mathrm{~m} / \mathrm{s}$ (see Table 1).

Table 1. Physical properties of the model.

\begin{tabular}{|c|c|c|c|c|c|c|c|c|}
\hline Cases & $\mathrm{Q}_{\text {fuel }}(\mathrm{N} \mathrm{l} / \mathrm{min})$ & $\mathrm{Q}_{\text {air }}(\mathrm{N} 1 / \mathrm{min})$ & $\dot{m}_{\text {fuel }}(\mathrm{kg} / \mathrm{s})$ & $\dot{m}_{\text {air }}(\mathrm{kg} / \mathrm{s})$ & $\mathrm{V}_{\mathrm{i}}(\mathrm{m} / \mathrm{s})$ & $\mathrm{V}_{\mathrm{e}}(\mathrm{m} / \mathrm{s})$ & $\mathbf{R}_{\mathrm{v}}$ & $\Phi$ \\
\hline Case $1: R_{v}<1$ & 15.75 & 150 & 0.00017 & 0.0032 & 4.98 & 2.8 & 0.56 & 1 \\
\hline Case $2: \mathrm{Rv}=1$ & 15.75 & 266 & 0.00017 & 0.0056 & 4.98 & 4.98 & 1 & 0.56 \\
\hline Case 3: $\mathrm{Rv}>1$ & 15.75 & 400 & 0.00017 & 0.0085 & 4.98 & 7.47 & 1.5 & 0.37 \\
\hline
\end{tabular}

In this paper, we study the impact of air velocity variation on the swirling diffusion flame. Thus, with a velocity of methane flow fixed at $4.98 \mathrm{~m} / \mathrm{s}$ (inlet velocity used in measurements), we used three air flow velocities of $2.8,4.98$ and $7.47 \mathrm{~m} / \mathrm{s}$ (see Table 1).

\section{Results and Discussion}

\subsection{Model Validation}

In order to validate the computational models, the numerical results of the mean axial and tangential velocity in non-reactive and reactive case were compared with the experimental data obtained in the same conditions. Figure 3 shows the radial profile of mean axial velocity under non-reacting and reacting conditions at several levels downstream of the burner exit. The results show that the trends of the axial velocity profile were similar under non-reacting and reacting cases. The central recirculation zone (CRZ) and the swirl jet, which are represented respectively by the minimum and the maximum of the velocity value, were well captured. For the isothermal case, the numerical results predicted the value of the maximum and minimum velocity in all locations. For the reacting case, the peak value of the mean axial velocity was well captured at $Z=10 \mathrm{~mm}$ and $Z=20 \mathrm{~mm}$. However, the prediction of CRZ was competitive. The difference between the numerical results and the SPIV results were due to the turbulence model. Figure 4 presents the contours of the mean axial velocity for non-reacting and reacting cases. The results are presented in the $(\mathrm{x}, \mathrm{z})$ plane downstream the burner exit. The predicted and measured mean axial velocity fields were qualitatively similar and the swirling flow behavior was well captured. It was characterized by the presence of a CRZ. According to these results, it can be seen that for the non-reacting case (Figure 4a), a good agreement was achieved. The value of negative velocity, which represents the CRZ, was around $-2 \mathrm{~m} / \mathrm{s}$. For the reacting case (Figure $4 \mathrm{~b}$ ), the experimental results show that the presence of the flame considerably affected the CRZ. The flame increased the CRZ width and decreased its length. Contrary to the experimental results, the presence of the flame did not affect the CRZ length for the numerical results but led to a decrease in its width in the burner exit. This can be explained by the effect of the flame and the use of a two-step mechanism, which cannot describe the full chemical reaction of $\mathrm{CH}_{4}$, thus it alters the CRZ. Nogenmyr et al. [43] has demonstrated that the complexity of the combustion kinetics affects the degree of agreement between the numerical and experimental reacting flows. The discrepancy between simulation and measurements (Figure 3b) can also be explained by the effect of the presence of the flame, which leads to an important gradient of temperature. Thermal agitation is very important around the reaction zone and the velocity of the flow changes considerably in this region. 

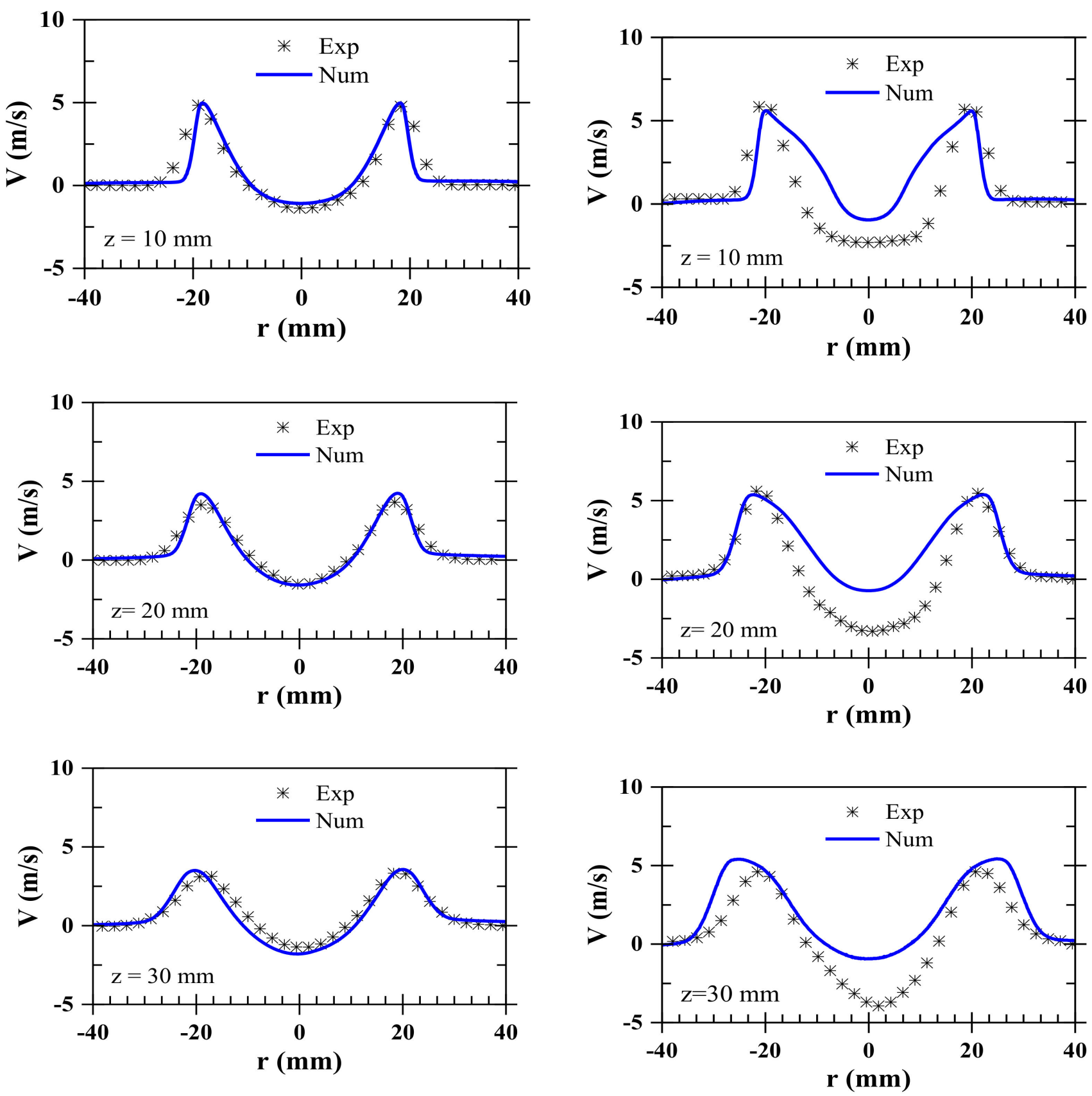

(a)

(b)

Figure 3. Obtained numerical profiles of radial mean axial velocity compared to experimental data for non-reacting and reacting cases; (a) non-reacting case; (b) reacting case.

Figure 5 presents the comparison between the numerical results and the experimental data for the mean tangential velocity profile at different positions defined by $Z=10 \mathrm{~mm}$, $Z=20 \mathrm{~mm}$ and $Z=30 \mathrm{~mm}$ downstream of the burner exit. It can be seen that the obtained computed results and the SPIV measurement were almost the same at each location for both non-reacting and reacting cases. The profile of mean tangential velocity has two peaks at $r=20 \mathrm{~mm}$ and $r=-20 \mathrm{~mm}$. Figure 6 shows the predicted and the measured mean tangential velocity under non-reacting and reacting conditions. For the isothermal case (Figure 6a), the results show that the numerical simulation and experimental measurement and are in good agreement. For the reacting case the tangential velocity contours are 
quite different; the presence of the flame improves the swirling velocity, especially in the longitudinal direction. This phenomenon can be explained by the effect of the important temperature gradient and especially in the reaction zone. The difference between the numerical and SPIV contours of tangential velocity relates to the CRZ width, which depends on the turbulence model. A good agreement was noted between the numerical results and the experimental measurements for the non-reacting and the reacting cases. Globally, it can be seen that the results provided by the KER turbulence model and the EDM of combustion were able to capture all physical phenomena in this case study.
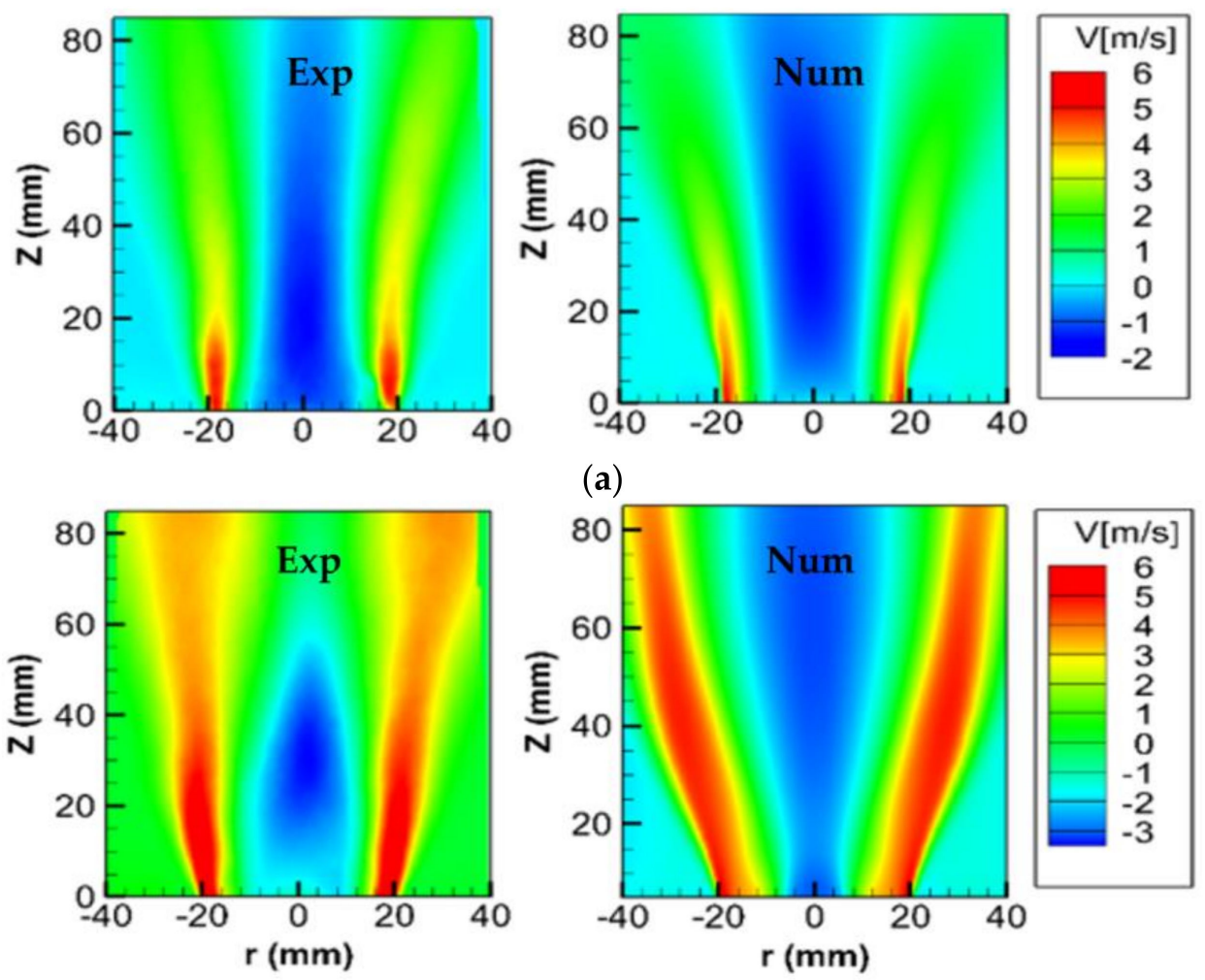

(a)

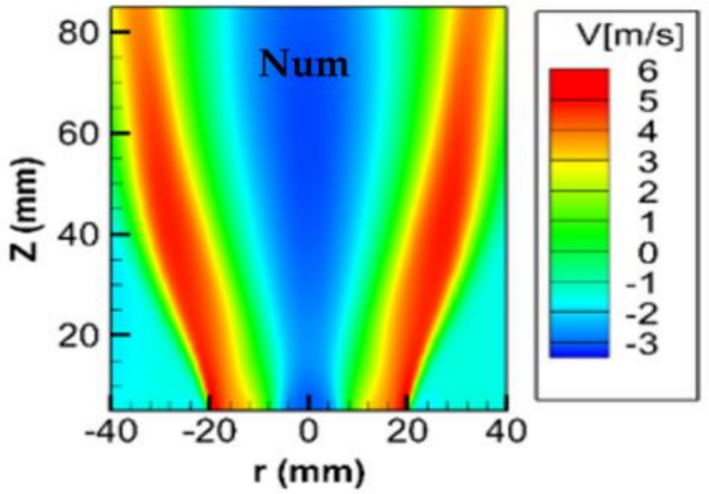

(b)

Figure 4. Numerical and experimental contours of mean axial velocity under non-reacting and reacting cases; (a) non-reacting case; (b) reacting case.

\subsection{Effect of the Velocity Ratio}

For a fixed initial fuel velocity and different initial values of air flow rate, as shown in Table 1, the turbulent kinetic energy (TKE), the temperature distribution, the consumption of methane and the distribution of oxygen and pollutant emissions were computed and analyzed.

\subsubsection{Turbulent Kinetic Energy}

Figure 7 shows the contours of turbulent kinetic energy obtained for three different velocity ratios, $R_{v}=0.5, R_{v}=1$ and $R_{v}=1.5$. The plots show that the TKE increases by increasing the velocity ratio. The turbulent kinetic energy reaches its maximum at the region of the swirl jet. Figure $8 \mathrm{a}-\mathrm{c}$ represents the profile of this parameter for three velocity ratios at different locations downstream of the burner exit $(Z=5,10,30$ and $60 \mathrm{~mm})$. By increasing the velocity ratio, the TKE profile displays the same behavior at the different locations. It can be seen that the maximum TKE value was reached for a velocity ratio of 1.5 . 

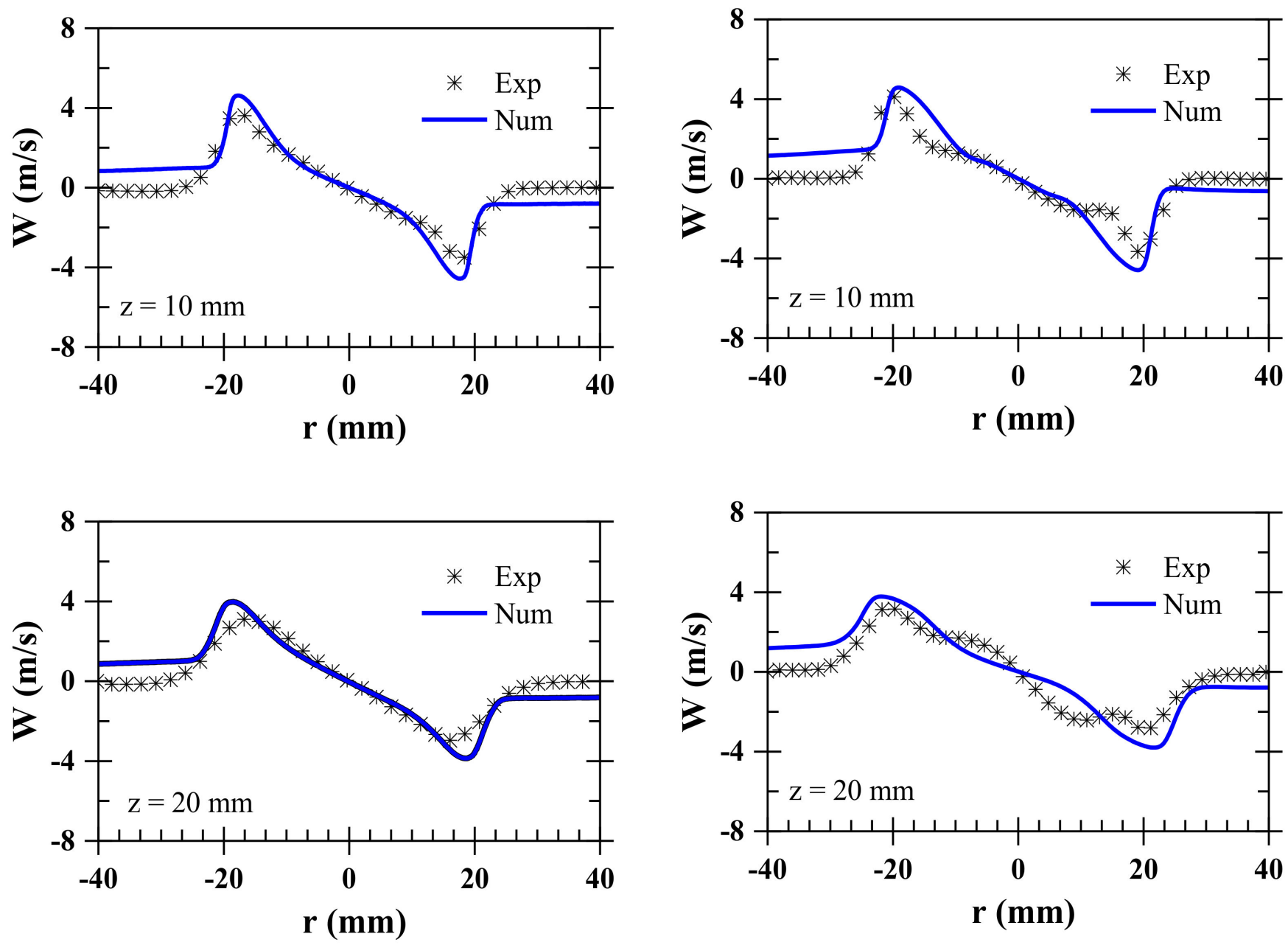

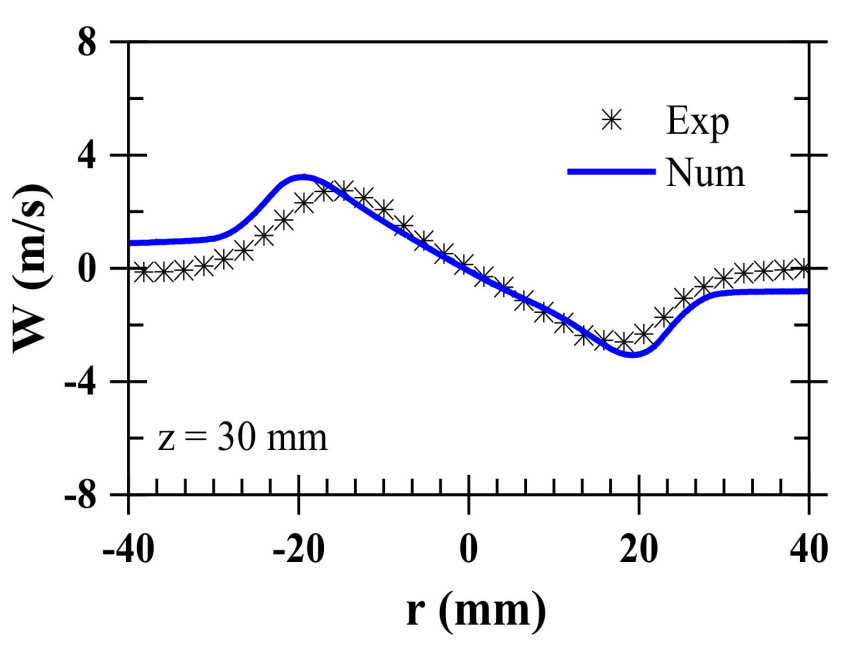

(a)

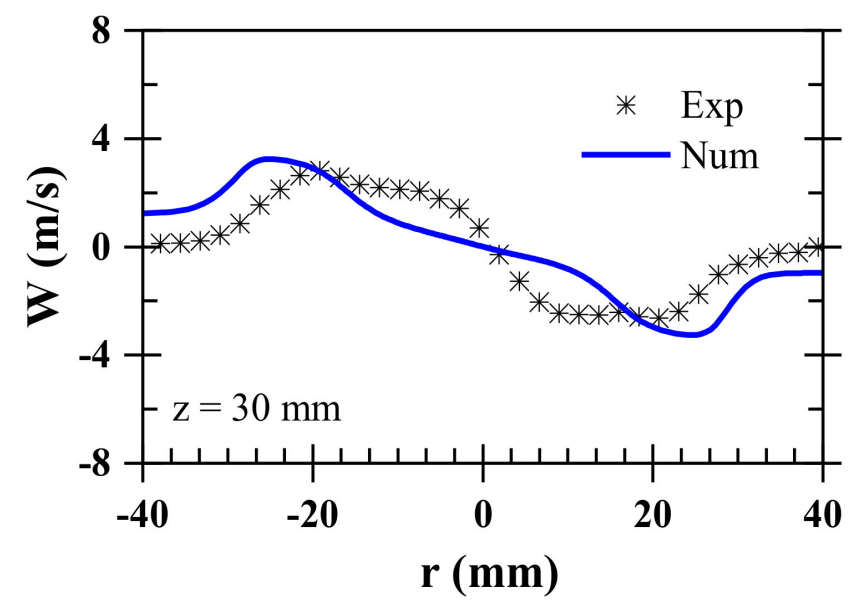

(b)

Figure 5. Obtained numerical profiles of the tangential velocity compared to experimental data for non-reacting and reacting cases; (a) non-reacting case; (b) reacting case. 

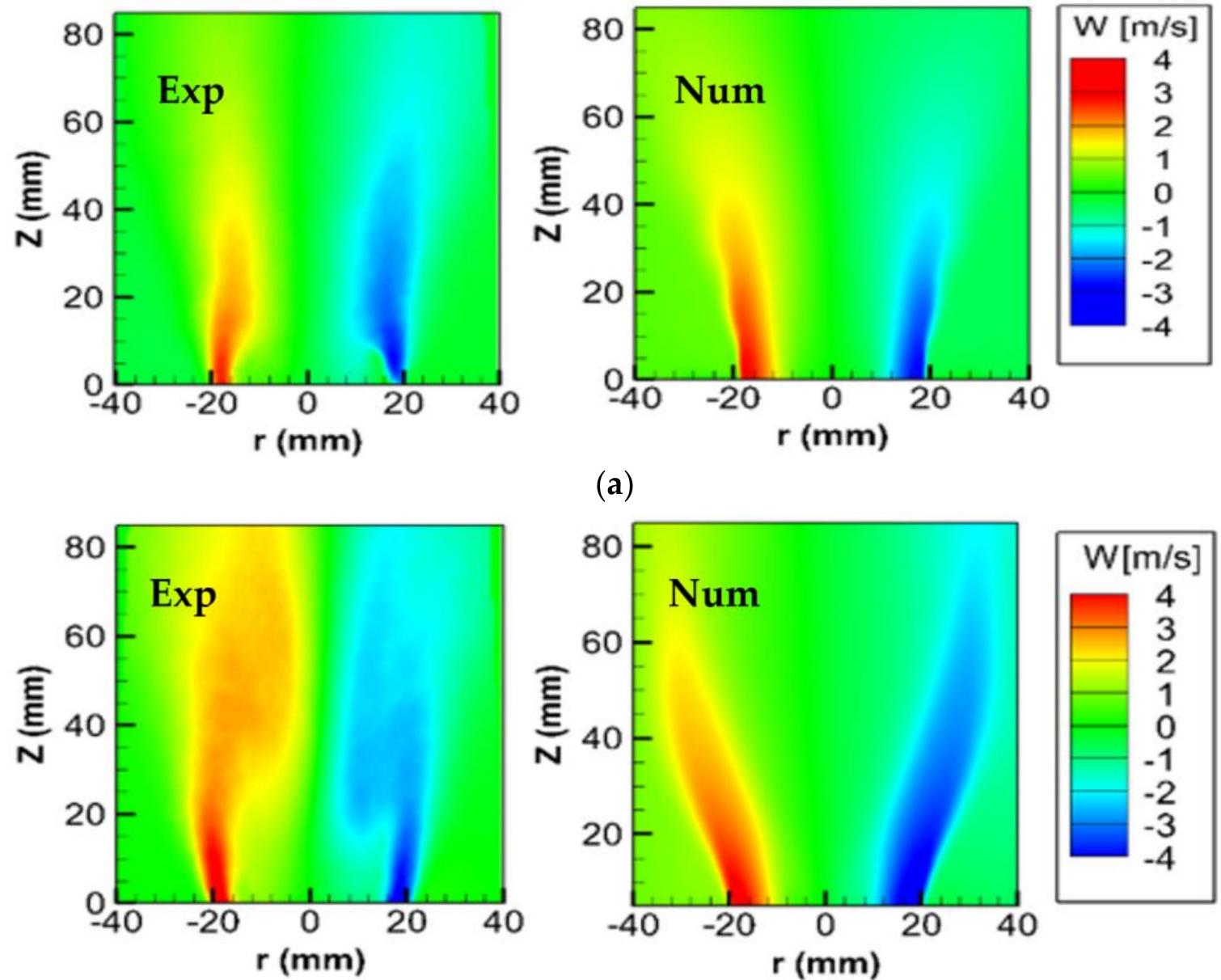

(a)

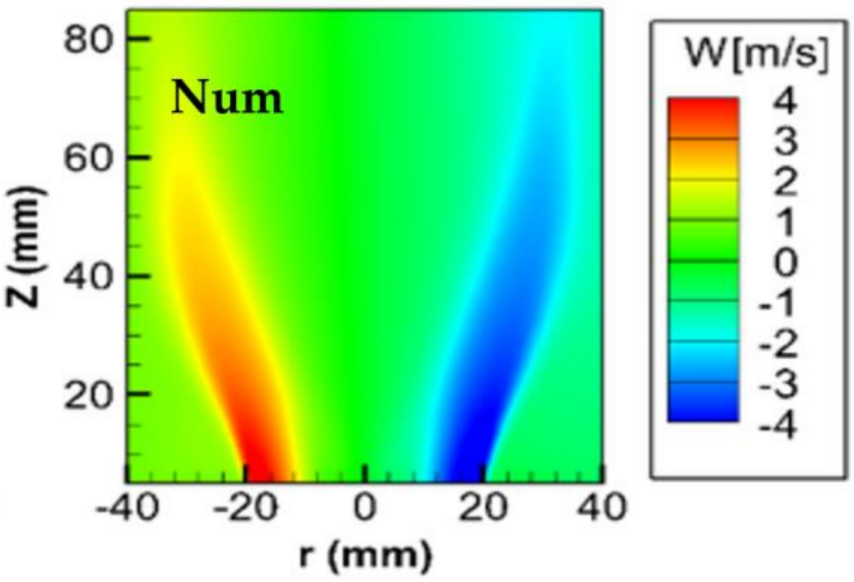

(b)

Figure 6. Obtained numerical contours of the tangential velocity compared to experimental data for non-reacting and reacting cases; (a) non-reacting case; (b) reacting case.

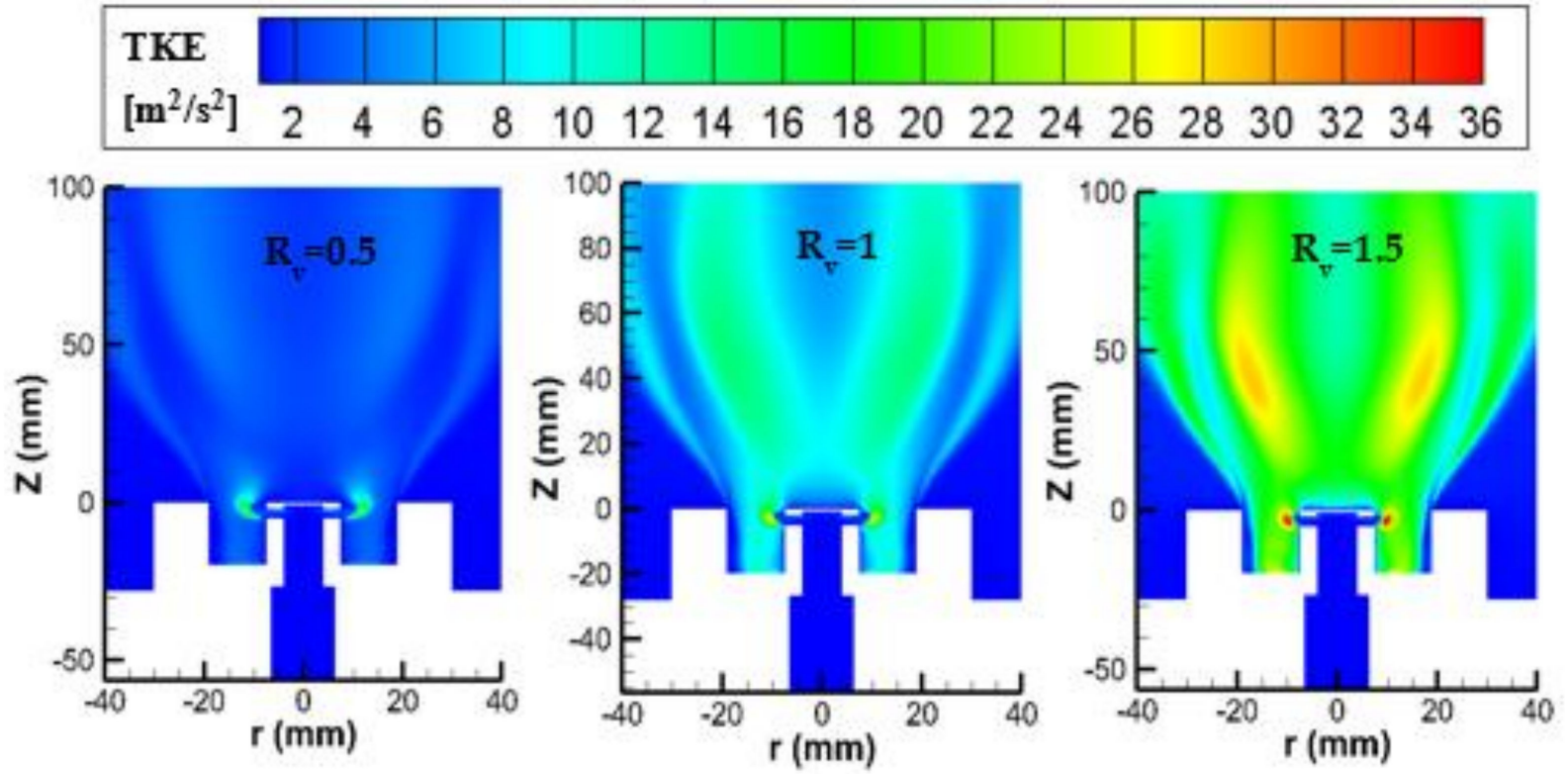

Figure 7. Contours of obtained numerical turbulent kinetic energy in the plane $(X, Z)$. 


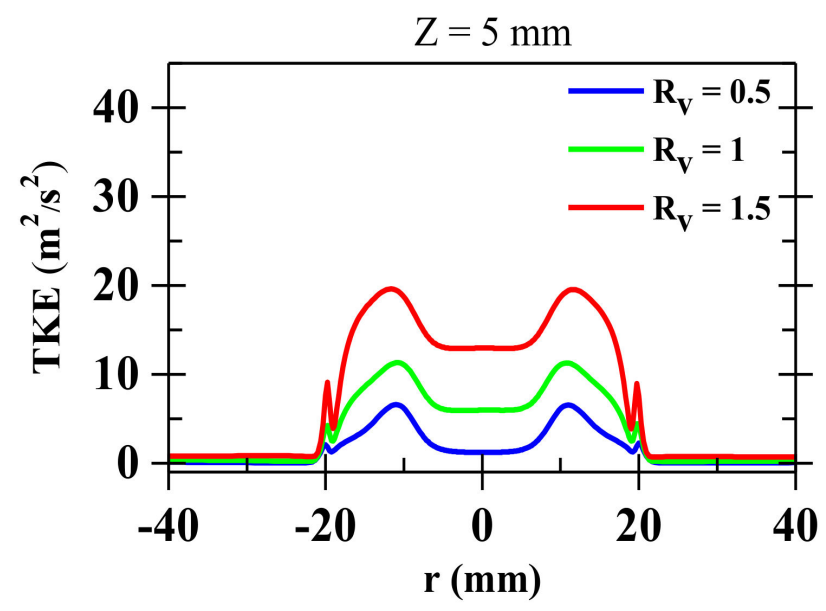

(a)

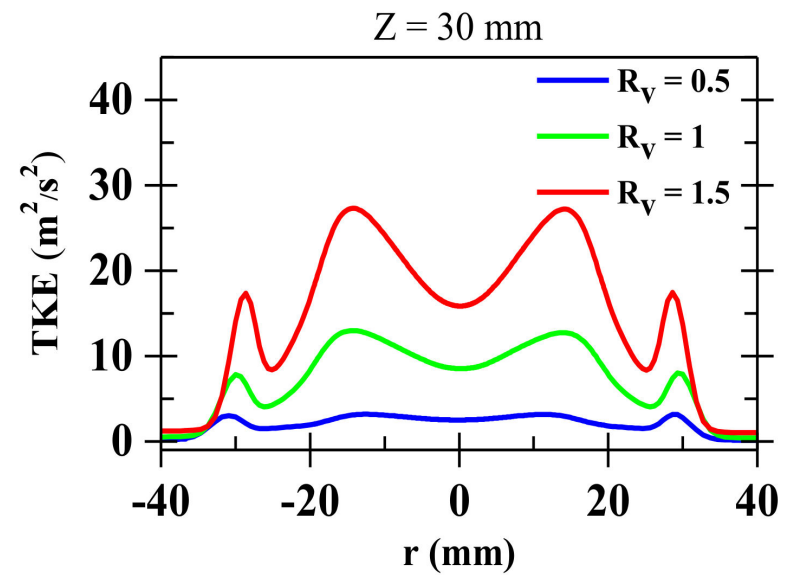

(c)

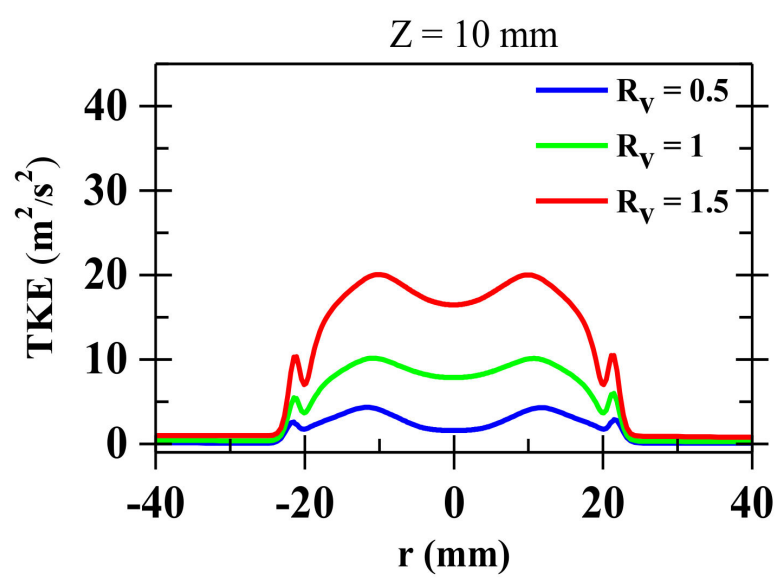

(b)

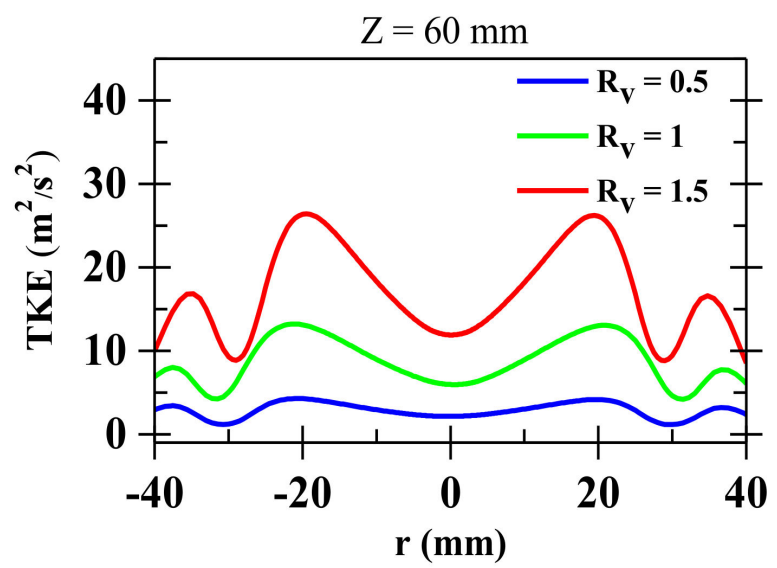

(d)

Figure 8. Computed turbulent kinetic energy $\left(\mathrm{m}^{2} / \mathrm{s}^{2}\right)$ for three velocity ratios obtained at different height locations; (a) $Z=5 \mathrm{~mm}$; (b) $Z=10 \mathrm{~mm}$; (c) $Z=30 \mathrm{~mm}$; (d) $Z=60 \mathrm{~mm}$.

For example, at a height of $30 \mathrm{~mm}$ from the burner exit, (Figure $8 \mathrm{~b}$ ), the TKE value was around $28 \mathrm{~m}^{2} / \mathrm{s}^{2}$ for $R_{v}=1.5$, whereas this value did not exceed $13 \mathrm{~m}^{2} / \mathrm{s}^{2}$ for $R_{v}=0.5$. The high axial velocity of the air jet increased the interactions between reactants, thus improving the mixing. The fluctuations reflect the degree of interaction between the different jets. They are generated by the velocity gradient between the different jets.

The computed kinetic energy is proportional to the fluctuations, since it is calculated based on the following equation:

$$
T K E=\frac{1}{2}\left[\left(U^{\prime}\right)^{2}+\left(V^{\prime}\right)^{2}+\left(W^{\prime}\right)^{2}\right]
$$

The kinetic energy of the turbulence underlines the advantage of the high velocity ratio for the increase in the turbulence intensity. The increase in TKE improves the mixing efficiency and the molecules of the oxidant and the fuel reacts more easily. Increasing the TKE leads to an increase in the velocity ratio, and thus the flame is more stable and becomes more attached to the burner.

\subsubsection{Temperature Distribution}

Figure 9 illustrates the temperature distribution as a function of the velocity ratio. For the three cases, the flame had a hot core that extended radially as z increased, surrounded by a relatively cooler reaction zone that separated the flame core from the outside environment. 
At a low velocity ratio $\left(R_{v}=0.5\right)$, the flame temperature extended into a large area in the computational domain. Figure 9 also shows that the augmentation of the inlet air velocity decreased the flame length and enhanced its stability.

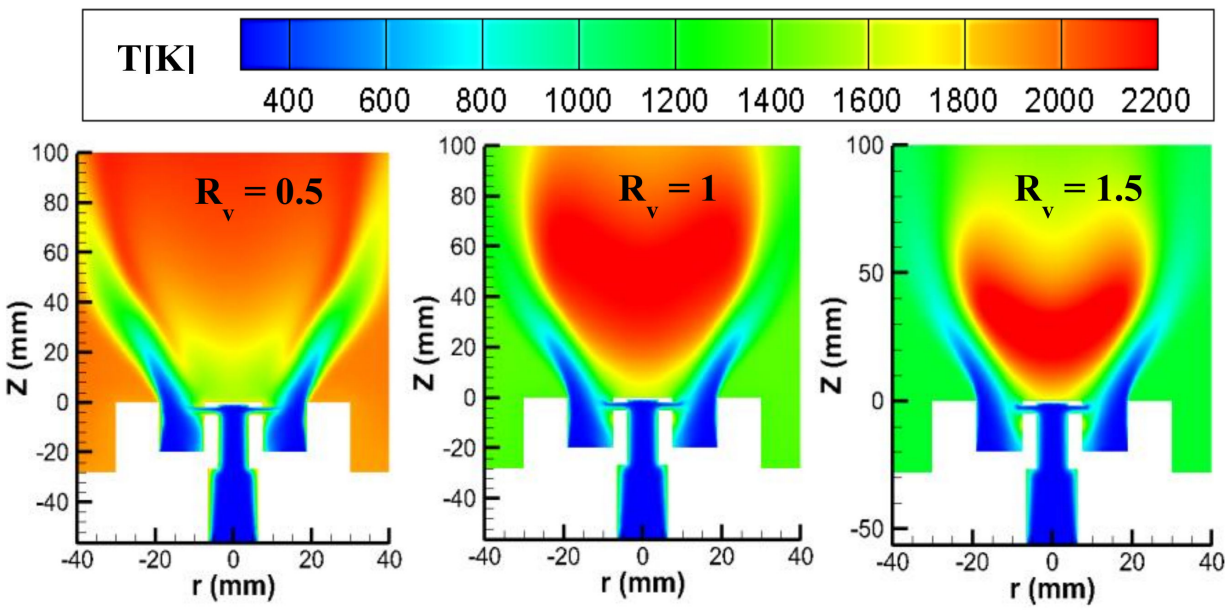

Figure 9. Contours of computed temperature distribution $T(K)$ in the plane $(X, Z)$.

Figure 10 shows the profiles of temperature distribution $\mathrm{T}(\mathrm{K})$ for three velocity ratios at different locations, $Z=5 \mathrm{~mm}, Z=10 \mathrm{~mm}, Z=30 \mathrm{~mm}$ and $Z=60 \mathrm{~mm}$. If the air velocity increases along with the increase of the velocity ratio, the temperature in the reaction zone increases. For example, at $\mathrm{Z}=30 \mathrm{~mm}$, the flame core was at $1800 \mathrm{~K}$ in the case of $R_{v}=0.5$, whereas for $R_{v}=1.5$, the temperature exceeded $2200 \mathrm{~K}$. The addition of air quantity decreased the flame length. It can be seen in Figure 9 that the flame moved to the burner exit when the velocity ratio increased. In addition, the reaction zone was reduced in volume as the velocity ratio increased, which is similar to the decrease in the global equivalence ratio when the velocity of air increases.

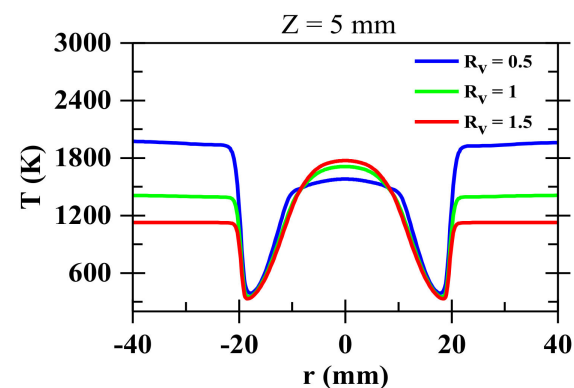

(a)

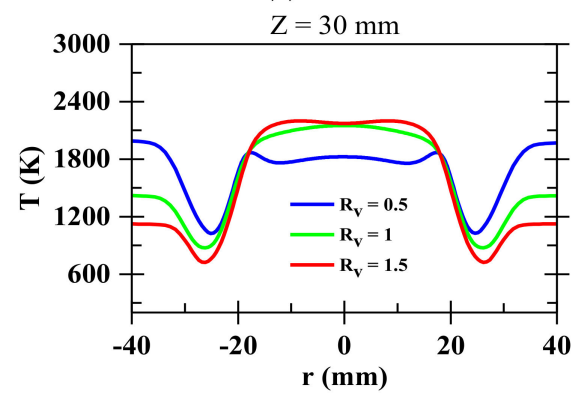

(c)

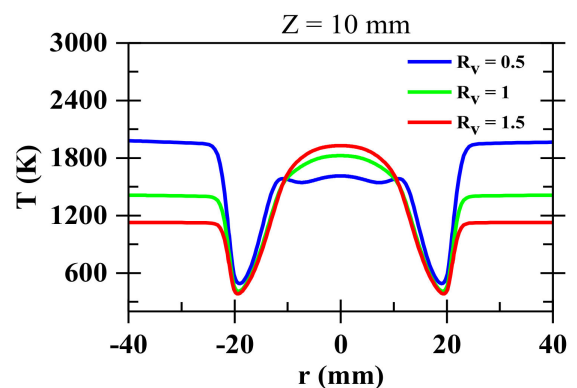

(b)

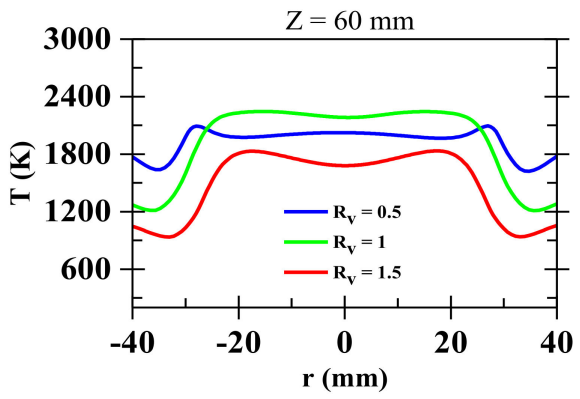

(d)

Figure 10. Computed temperature profiles for three velocity ratios obtained at four heights; (a) $Z=5 \mathrm{~mm}$; (b) $Z=10 \mathrm{~mm}$; (c) $Z=30 \mathrm{~mm}$; (d) $Z=60 \mathrm{~mm}$. 


\subsubsection{Mass Fraction of $\mathrm{CH}_{4}$ and $\mathrm{O}_{2}$}

Figure 11 shows the radial numerical profiles of the methane mass fraction obtained for different velocity ratios and presented at three locations downstream of the burner exit ( $Z=5 \mathrm{~mm}, Z=10 \mathrm{~mm}, Z=30 \mathrm{~mm}$ and $Z=60 \mathrm{~mm}$ ). The mass fraction of the methane presented a maximum on the burner axis $(-10<\mathrm{r}<10)$. The mass fraction decreased when the radial position $r$ increased and moved toward zero away from the burner center. It can be seen that the maximum mass fraction of the fuel decreased when the quantity of oxygen increased, along with an increase in the velocity ratio. For a low velocity ratio $\left(R_{v}=0.5\right)$ and at a position near the burner exit $(Z=10 \mathrm{~mm})$, the mass fraction of the fuel was equal to 0.15 at $\mathrm{r}=15 \mathrm{~mm}$. At the same location and for a velocity ratio of 1.5 , the fuel mass fraction was equal to 0.1 . Figure 11 represents the variation in the fuel mass fraction obtained for three different velocity ratios and for different heights. It can be seen that with different velocity ratios the quantity of $\mathrm{CH}_{4}$ consumed by the combustion reaction depended on the reaction zone displacement. At $Z=60 \mathrm{~mm}$ (Figure 11c) the maximum mass fraction equaled 0.018 for $R_{v}=0.5$ and equaled zero for $R v=1$ and $R v=1.5$. This means that at a distance of $60 \mathrm{~mm}$ downstream of the burner exit, the methane was completely consumed by the combustion reaction.

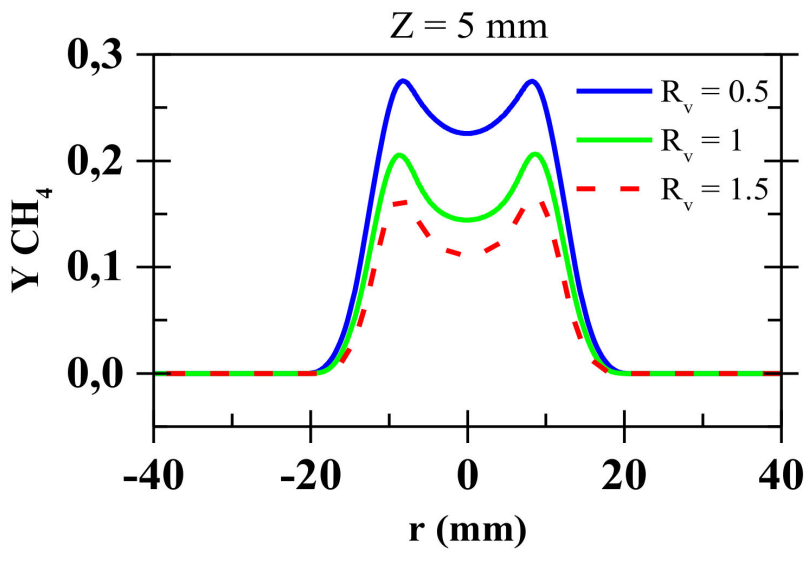

(a)

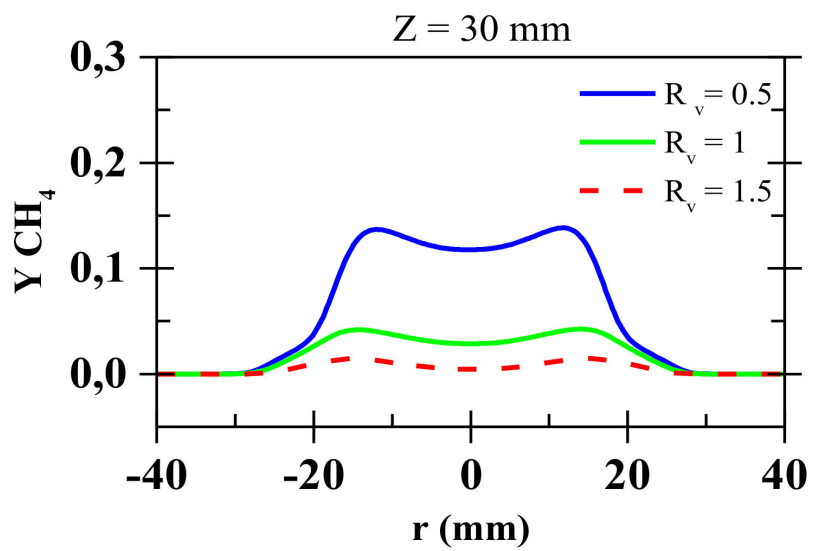

(c)

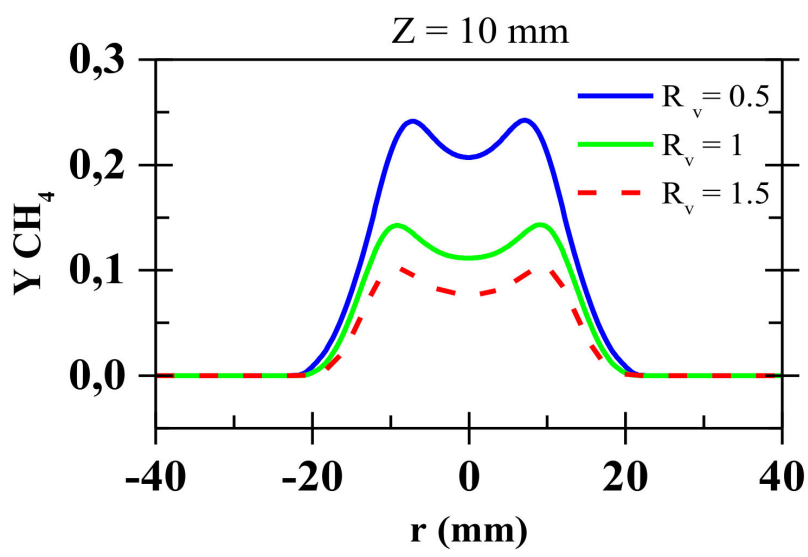

(b)

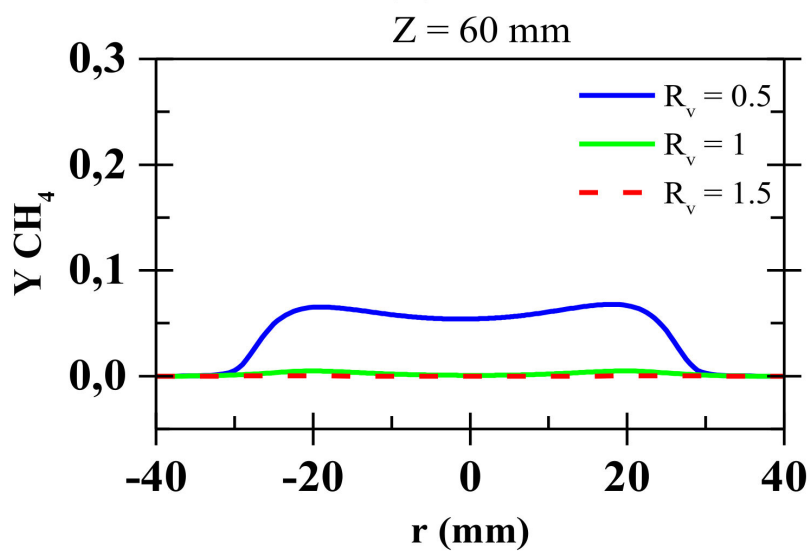

(d)

Figure 11. Radial profiles of the fuel mass fractions obtained for different velocity ratios and at four height locations; (a) $Z=5 \mathrm{~mm}$; (b) $Z=10 \mathrm{~mm}$; (c) $Z=30 \mathrm{~mm}$; (d) $Z=60 \mathrm{~mm}$.

Figure 12 shows the obtained radial profiles of the oxygen mass fractions at different heights ( $5 \mathrm{~mm}, 10 \mathrm{~mm}, 30 \mathrm{~mm}$ and $60 \mathrm{~mm}$ downstream of the burner exit). The highest mass fraction of $\mathrm{O}_{2}$ was located at the swirl jet (at $\mathrm{r}=-20 \mathrm{~mm}$ and $\mathrm{r}=20 \mathrm{~mm}$ ). Near the burner exit (Figure 12a), the variation in the mass fraction of the oxygen presents a 
minimum at the radial position of $\mathrm{r}$ between $-10 \mathrm{~mm}$ and $10 \mathrm{~mm}$, which represents the reactive zone, where the mixing between the fuel and the air is nearly in balance. At $\mathrm{Z}=30 \mathrm{~mm}$ (Figure 12b), the radial position of the maximum increases when the velocity ratio increases. Thus, the flame becomes thinner by the addition of air. Moving away from the burner exit, at $Z=60 \mathrm{~mm}$ (Figure 12c) the mass fraction of the oxygen value is around zero in the flame zone for $R_{v}=0.5$ and $R v=1$, indicating that the quantity of oxygen injected by the burner is completely consumed by the reaction. For $R_{V}=1.5$, it can be seen that the mass fraction of the oxygen in the reactive zone is around 0.1 .

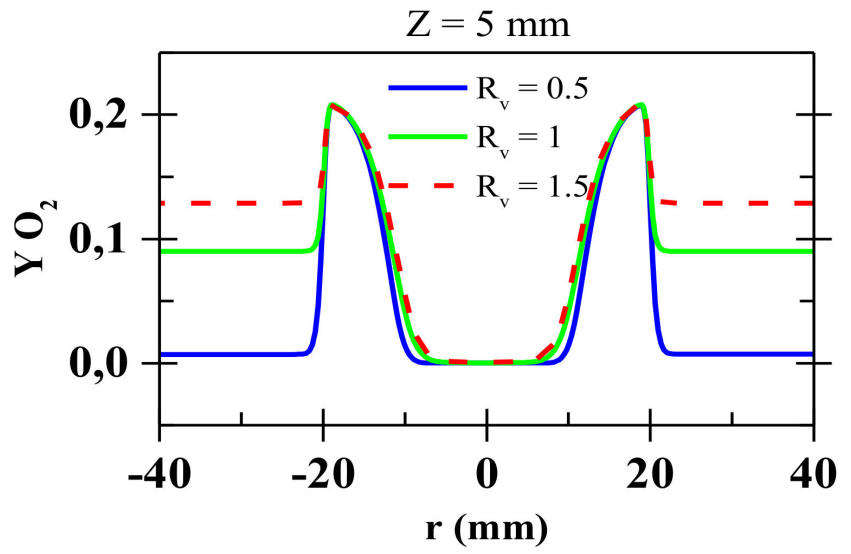

(a)

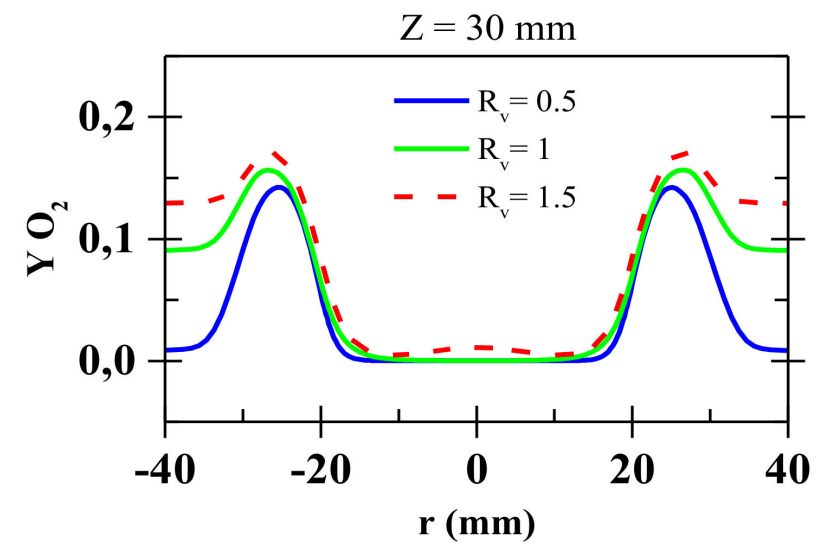

(c)

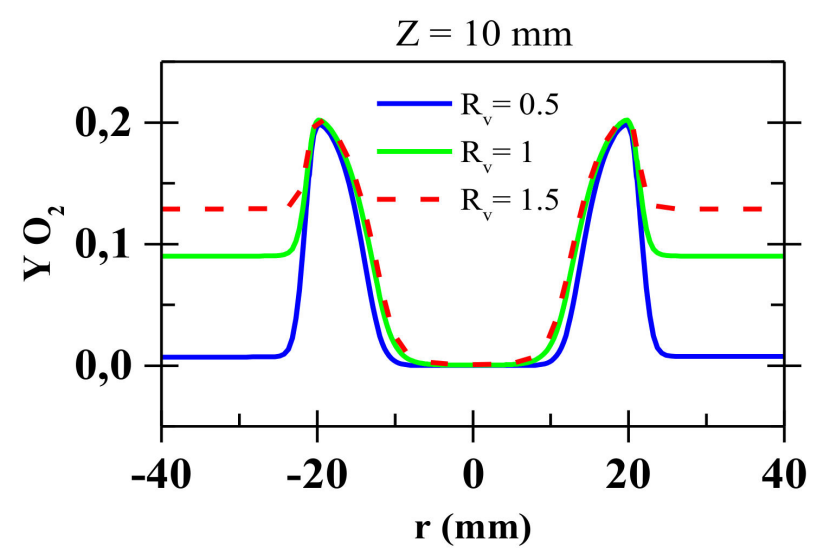

(b)

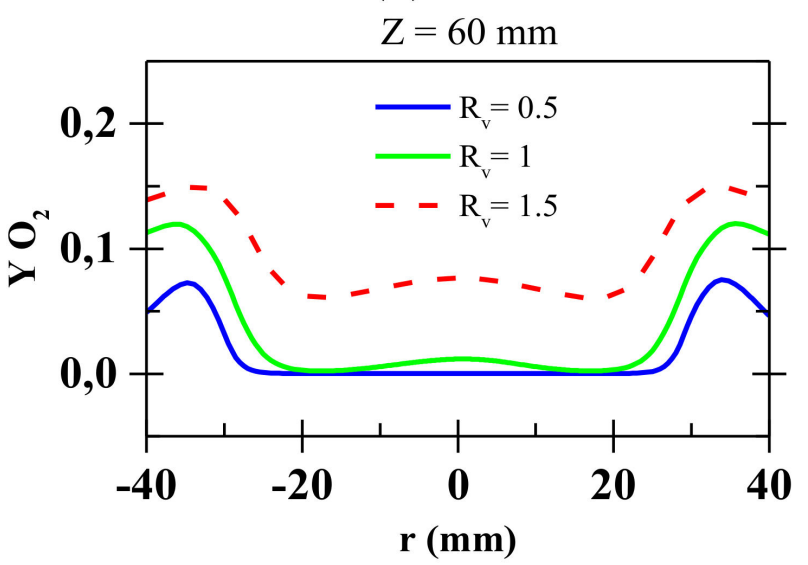

(d)

Figure 12. Computed radial profiles of oxygen mass fractions for different velocity ratios and at four heights; (a) $Z=5 \mathrm{~mm}$; (b) $Z=10 \mathrm{~mm}$; (c) $Z=30 \mathrm{~mm}$; (d) $Z=60 \mathrm{~mm}$.

\subsubsection{Pollutant Emissions}

Figure 13 shows the obtained contours of the $\mathrm{CO}$ mass fraction in the combustion chamber for three velocity ratios. It can be seen that the $\mathrm{Y}_{\mathrm{CO}}$ distribution takes a $\mathrm{V}$ shape like the flame. The maximum CO concentrations are shown in the swirl jet and the central recirculation zone contains only a small quantity. Figure 14 illustrates the profile of the $C O$ variation at $Z=60 \mathrm{~mm}$ for three velocity ratios. The results indicate that increasing the velocity ratio decreases $C O$ formation. If the velocity ratio increases from $R_{v}=0.5$ to $\mathrm{Rv}=1.5$, the mass fraction of $\mathrm{CO}$ decreases from 0.008 to 0.001 . 

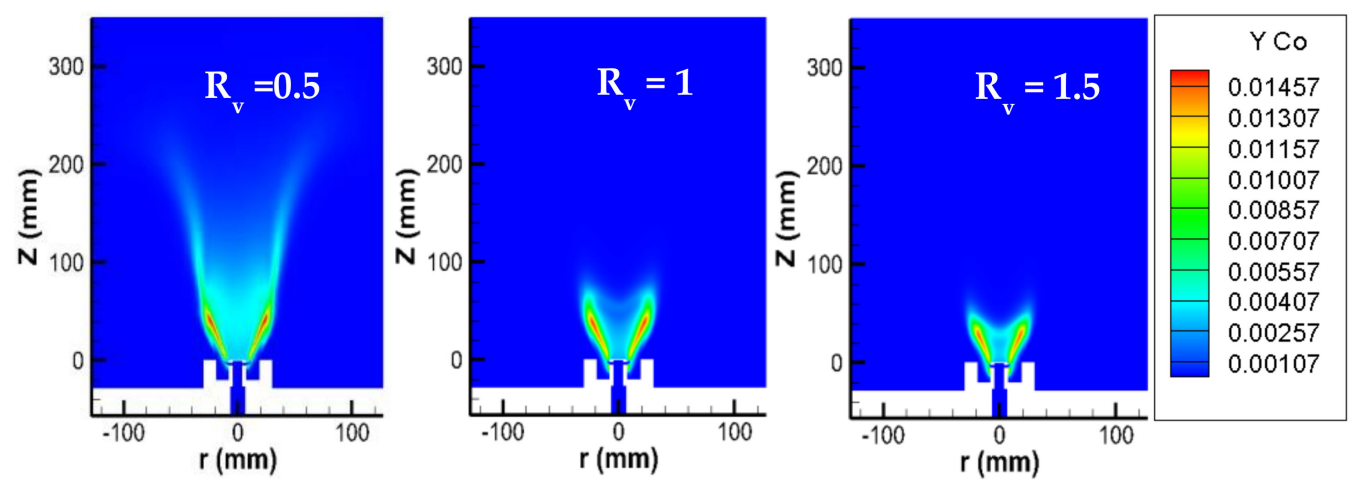

Figure 13. Computed contours of $C O$ mass fractions obtained in the plane $(X, Z)$.

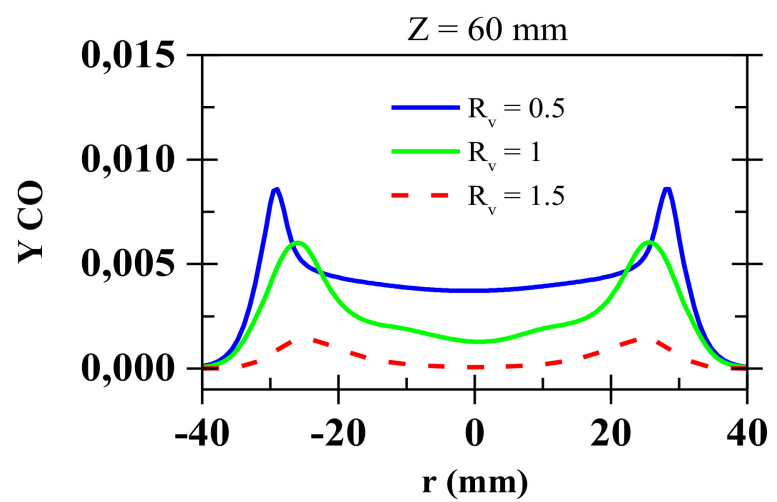

Figure 14. Radial profiles of $C O$ mass fractions for different velocity ratios at $Z=60 \mathrm{~mm}$.

Increasing the equivalence ratio prompts an increment in the oxygen mass fraction, as shown in Figure 12. The increase in the oxygen concentration promotes $\mathrm{CO}$ conversion into $\mathrm{CO}_{2}$ [35].

Figure 15 displays the obtained radial profiles of the NOx mole fraction for different velocity ratios at $Z=60 \mathrm{~mm}$. The distribution of the NOx fraction also depends on the velocity ratio. For $R_{v}=1$ and $R v=1.5$, the maximum $N O x$ concentrations are shown in the reaction zone. The main parameter that affects the NOx emission is the temperature. If the velocity ratio increases from $R_{V}=0.5$ to $R v=1$, the NOx emission increases. This augmentation can be explained by the increases in flame temperature (Figure 10) via the thermal NO mechanism. The highest velocity ratio $\left(R_{v}=1.5\right)$ causes a decrease in NOx formation because of the decrease in the temperature value in the flame zone at $\mathrm{Z}=60 \mathrm{~mm}$ (Figure 10c).

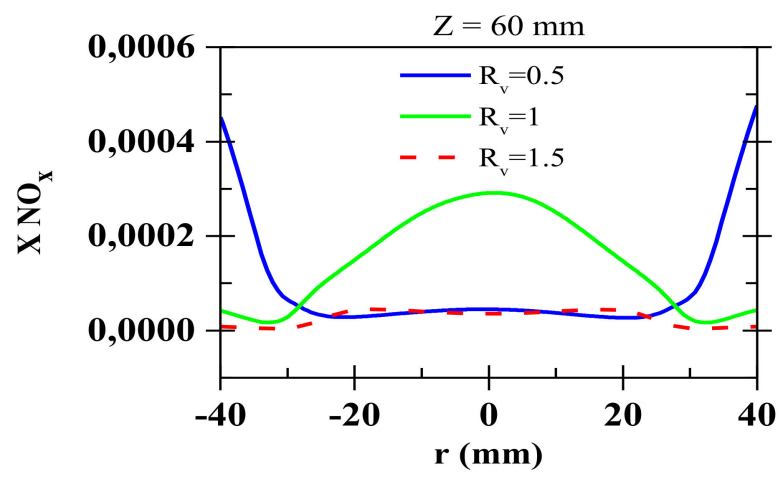

Figure 15. Radial profiles of NOx mole fractions obtained for different velocity ratios at $\mathrm{Z}=60 \mathrm{~mm}$. 


\section{Conclusions}

An experimental and numerical investigation of swirling flow under non-reacting and reacting conditions provided by a coaxial burner with a radial injection of fuel was presented. A turbulent methane/air diffusion flame was studied for a high swirl number $\left(S_{n}=1.4\right)$. The stereoscopic particle image velocimetry (stereo-PIV) technique was used to measure the dynamics of non-premixed swirling flows for isothermal and reacting cases. The numerical results were calculated using the RANS turbulence approach, associated with the eddy dissipation combustion model in the reacting case. The numerical models were validated by comparing the computed results with the measurement data obtained for isothermal and reacting cases in the same conditions. The effect of the velocity ratio on the turbulent swirling diffusion flame, particularly in the case where the fuel is injected across the oxidizer, was numerically investigated. The results of this study reveal the following:

- For a fixed inlet fuel velocity, the variation of inlet air velocity in a coaxial burner configuration causes a change in the dynamics of the flame. The increase in the velocity ratio leads to an increase in the turbulent kinetic energy and subsequently improves the mixing.

- The radial injection of fuel induces a partial premixing between reactants, which affects the flame behavior, in particular the flame stabilization.

- Increasing the velocity ratio causes a modification of the flame morphology and the flame becomes well attached to the burner.

- The addition of air decreases the flame length and the height of liftoff and the flame becomes more attached to the burner.

- Pollutant emission results revealed that the increase in the velocity ratio reduced the $\mathrm{CO}$ emissions caused by the temperature variation.

Author Contributions: Conceptualization, S.C., A.H., T.B.; methodology, S.C., A.H., T.B.; software, S.C., A.H., M.C.; validation, S.C., A.H., H.Z., M.C., T.B.; formal analysis, S.C., A.H., H.Z., M.C., T.B.; investigation, S.C., A.H., H.Z., M.C., T.B.; writing-original draft preparation, S.C., A.H., T.B.; writing-review and editing, S.C., A.H., T.B.; visualization, S.C., A.H., H.Z., M.C., T.B.; supervision, A.H., T.B.; project administration, A.H., T.B. All authors have read and agreed to the published version of the manuscript.

Funding: This research received no external funding.

Institutional Review Board Statement: Not applicable.

Informed Consent Statement: Not applicable.

Data Availability Statement: Data sharing not applicable. No new data were created or analyzed in this study. Data sharing is not applicable to this article.

Acknowledgments: The authors are grateful for the financial support for this work provided by the programs LABEX CAPRYSSES (ANR-11-LABX-0006-01) and EranetMed II (RenewValue project). The financial support given by the Tunisian state for S. Chakchak's stay in France is gratefully acknowledged.

Conflicts of Interest: The authors declare no conflict of interest.

\section{References}

1. Tang, F.; Li, L.; Wang, Q.; Shi, Q. Effect of cross-wind on near-wall buoyant turbulent diffusion flame length and tilt. Fuel 2016, 186, 350-357. [CrossRef]

2. Li, X.; Dai, Z.; Guo, Q.; Liang, Q.; Wang, F. Experimental and numerical study of mild combustion in a bench scale natural gas partial oxidation gasifier. Fuel 2017, 193, 197. [CrossRef]

3. Merlo, N.; Boushaki, T.; Chauveau, C.; de Persis, S.; Pillier, L.; Sarh, B.; Gökalp, I. Experimental study of oxygen enrichment effects on turbulent non-premixed swirling flames. Energy Fuels 2013, 27, 6191-6197. [CrossRef]

4. Zaidaoui, H.; Boushaki, T.; Sautet, J.C.; Chauveau, C.; Sarh, B.; Gökalp, I. Effects of $\mathrm{CC}_{2}$ dilution and $\mathrm{O}_{2}$ enrichment on non-premixed turbulent $\mathrm{ch}_{4}$-air flames in a swirl burner. Combust. Sci. Technol. 2018, 190, 784-802. [CrossRef]

5. Yilmaz, I. Effect of swirl number on combustion characteristics in a natural gas diffusion flame. J. Energy Resour. Technol. 2013, 135, 042204. [CrossRef] 
6. Acharya, V.; Lieuwen, T. Effect of azimuthal flow fluctuations on flow and flame dynamics of axisymmetric swirling flames. Phys. Fluids 2015, 27, 105106. [CrossRef]

7. Jerzak, W.; Kuźnia, M. Experimental study of impact of swirl number as well as oxygen and carbon dioxide content in natural gas combustion air on flame flashback and blow-off. J. Nat. Gas Sci. Eng. 2016, 29, 46-54. [CrossRef]

8. Iyogun, C.O.; Birouk, M.; Kozinski, J.A. Experimental investigation of the effect of fuel nozzle geometry on the stability of a swirling non-premixed methane flame. Fuel 2011, 90, 1416-1423. [CrossRef]

9. Seepana, S.; Jayanti, S. Experimental studies of flame extinction in a swirl-stabilized oxy-fuel burner. Fuel 2012, 93, 75-81. [CrossRef]

10. Gupta, A.K.; Lilley, D.G.; Syred, N. Swirl Flows; Abacus Press: London, UK, 1984.

11. Syred, N. A review of oscillation mechanisms and the role of the precessing vortex core (PVC) in swirl combustion systems. Prog. Energy Combust. Sci. 2006, 32, 93-161. [CrossRef]

12. Boushaki, T.; Sautet, J.-C.; Labegorre, B. Control of flames by tangential jet actuators in oxy-fuel burners. Combust. Flame 2009, 156, 2043-2055. [CrossRef]

13. Boushaki, T.; Merlo, N.; de Persis, S.; Chauveau, C.; Göalp, I. Experimental investigation of CH4-air-O2 turbulent swirling flames by SPIV. Exp. Therm. Fluid Sci. 2019, 106, 87-99. [CrossRef]

14. Khodabandeh, E.; Moghadasi, H.; Safari Pour, M.; Ersson, M.; Jönsson, P.G.; Rosen, M.A.; Rahbari, A. CFD study of non-premixed swirling burners: Effect of turbulence models. Chin. J. Chem. Eng. 2020, 28, 1028-1038. [CrossRef]

15. Wegner, B.; Maltsev, A.; Schneider, C.; Sadiki, A.; Dreizler, A.; Janicka, J. Assessment of unsteady RANS in predicting swirl flow instability based on LES and experiments. Int. J. Heat Fluid Flow 2004, 25, 528-536. [CrossRef]

16. Gupta, A.; Kumar, R. Three-dimensional turbulent swirling flow in a cylinder: Experiments and computations. Int. J. Heat Fluid Flow 2007, 28, 249-261. [CrossRef]

17. Jones, W.P.; Lentini, D. A realizable non-linear eddy viscosity/diffusivity model for confined swirling flows. Int. J. Heat Fluid Flow 2008, 29, 1612-1627. [CrossRef]

18. Mansouri, Z.; Aouissi, M.; Boushaki, T. Detached eddy simulation of high turbulent swirling reacting flow in a premixed model burner. Combust. Sci. Technol. 2016, 188, 1777-1798. [CrossRef]

19. Fu, J.; Tang, Y.; Li, J.; Ma, Y.; Chen, W.; Li, H. Four kinds of the two-equation turbulence model's research on flow field simulation performance of DPF's porous media and swirl-type regeneration burner. Appl. Therm. Eng. 2016, 93, 397-404. [CrossRef]

20. Ries, L.; Carvalho, J.; Nascimento, M.A.R.; Rodrigives, L.O.; Dias, F.; Sobrinho, P.M. Numerical modeling of flow through an industrial burner orifice. Appl. Therm. Eng. 2014, 67, 201-213. [CrossRef]

21. Mansouri, Z.; Boushaki, T. Experimental and numerical investigation of turbulent isothermal and reacting flows in non-premixed swirl burner. Int. J. Heat Fluid Flow 2018, 72, 200-213. [CrossRef]

22. Mansouri, Z.; Boushaki, T. Investigation of large-scale structures of annular swirling jet in a non-premixed burner using delayed detached eddy simulation. Int. J. Heat Fluid Flow 2019, 77, 217-231. [CrossRef]

23. Hidouri, A.; Gazzah, M.H.; Ben Tïcha, H.; Sassi, M. Dynamic and scalar turbulent fluctuation in a diffusion flame of anaxisymmetric methane jet into air. Comput. Mech. 2003, 31, 253-261. [CrossRef]

24. Hidouri, A.; Yahya, N.; Boushaki, T.; Sadiki, A.; Sautet, J.C. Numerical and experimental investigation of turbulent three separated jets. J. Appl. Therm. Eng 2016, 104, 153-161. [CrossRef]

25. Hidouri, A.; Chrigui, M.; Boushaki, T.; Sadiki, A.; Janicka, J. Large eddy simulation of two isothermal and reacting turbulent separated oxy-fuel jets. Fuel 2017, 192, 108-120. [CrossRef]

26. Yahya, N.; Hidouri, A.; Chrigui, M.; Omri, A. LES modeling of non-premixed turbulent Oxy-Fuel combustion supplied by three separated jets. Combust. Sci. Technol. 2016, 188, 1220-1238.

27. Achim, D.; Naser, J.; Morsi, Y.S.; Pascoe, S. Numerical investigation of full scale coal combustion model of tangentially fired boiler with the effect of mill ducting. Heat Mass Transf. 2009, 46, 1-13. [CrossRef]

28. Lopez-Parra, F.; Turan, A. Computational study on the effects of non-periodic flow perturbations on the emissions of soot and NOx in a confined turbulent methane/air diffusion flame. Combust. Sci. Technol. 2007, 179, 1361-1384. [CrossRef]

29. Baik, J.S.; Kim, Y.J. Effect of nozzle shape on the performance of high velocity oxygen-fuel thermal spray system. Surf. Coat. Technol. 2008, 202, 5457-5462. [CrossRef]

30. Rehab, H.; Villermaux, E.; Hopfinger, E.J. Flow regimes of large-velocity-ratio coaxial jets. J. Fluid. Mech. 1997, 345, 357-381. [CrossRef]

31. Schumaker, S.A.; Driscoll, J.F. Mixing lengths of coaxial jets in a rocket combustor configuration using acetone PLIF. In Proceeding of the 43rd AIAA/ASME/SAE ASEE Joint Propulsion Conference and Exhibit, Cincinnati, OH, USA, 8-11 July 2007.

32. Schumaker, S.A.; Driscoll, J.F. Mixing properties of coaxial jets with large velocity ratios and large inverse density ratios. Phys. Fluid 2012, 24, 1-22.

33. Wu, K.T.; Essenhigh, R.H. Mapping and structure of inverse diffusion flames of methane. Combust Inst. 1984, 20, 1925-1932. [CrossRef]

34. Imine, B.; Saber-Bendhina, A.; Imine, O.; Gazzah, M.H. Effects of a directed co-flow on a non-reactive turbulent jet with variable density. Heat Mass Transf. 2005, 42, 39-50. [CrossRef]

35. Kim, T.Y.; Choi, S.; Kim, H.K.; Jeung, I.; Koo, J.; Kwon, O.C. Combustion properties of gaseous CH4/O2 coaxial jet flames in a single-element combustor. Fuel 2016, 184, 28-35. [CrossRef] 
36. Choi, S.; Kim, T.Y.; Kim, H.K.; Jeung, I.; Koo, J.; Kwon, O.C. Combustion stability of gaseous CH4/O2 and H2/O2 coaxial jet flames in a single-element combustor. Energy 2017, 132, 57-64. [CrossRef]

37. Beér, J.M.; Chigier, N.A. Combustion Aerodynamics; Applied Sci Publishers Ltd.: London, UK, 1972.

38. Moussa, O.; Driss, Z. Numerical investigation of the turbulence models effect on the combustion characteristics in a non-premixed turbulent flame methane-air. Am. J. Energy Res. 2017, 5, 85-93.

39. Bulat, M.P.; Bulat, P.V. Comparison of turbulence models in the calculation of supersonic separated flows. World Appl. Sci. J. 2013, $27,1263-1266$.

40. Magnussen, R.; Hjertager, B.H. On mathematical modeling of turbulent combustion with special emphasis on soot formation and combustion. Symp. Int. Combust. 1976, 16, 719-729. [CrossRef]

41. ANSYS FLUENT. Academic Research. Release 16.0. Help System, FLUENT User Guide; ANSYS Inc.: Canonsburg, PA, USA, 2016.

42. Wang, P. The model constant A of the eddy dissipation model. Progr. Comput. Fluid Dyn. Int. J. 2016, 16, 118. [CrossRef]

43. Nogenmyr, K.J.; Fureby, C.; Bai, X.S.; Petersson, P.; Collin, R.; Linne, M. Large eddy simulation and laser diagnostic studies on a low swirl stratified premixed flame. Combust. Flame 2009, 156, 25-36. [CrossRef] 